\section{Pacific Northwest}

National Laboratory

Operated by Battelle for the

U.S. Department of Energy

\title{
PNNL OS3700 Tritium Monitoring System Software and Hardware Operations Manual Rev. 0
}

\author{
JM Barnett \\ DM Carrell \\ DJ Duchsherer \\ DD Douglas \\ DR Sisk \\ GL Carter
}

November 2005

Prepared for the U.S. Department of Energy under Contract DE-AC05-76RL01830 


\title{
DISCLAIMER
}

This report was prepared as an account of work sponsored by an agency of the United States Government. Neither the United States Government nor any agency thereof, nor Battelle Memorial Institute, nor any of their employees, makes any warranty, express or implied, or assumes any legal liability or responsibility for the accuracy, completeness, or usefulness of any information, apparatus, product, or process disclosed, or represents that its use would not infringe privately owned rights. Reference herein to any specific commercial product, process, or service by trade name, trademark, manufacturer, or otherwise does not necessarily constitute or imply its endorsement, recommendation, or favoring by the United States Government or any agency thereof, or Battelle Memorial Institute. The views and opinions of authors expressed herein do not necessarily state or reflect those of the United States Government or any agency thereof.

\author{
PACIFIC NORTHWEST NATIONAL LABORATORY \\ operated by \\ BATTELLE \\ for the \\ UNITED STATES DEPARTMENT OF ENERGY \\ under Contract DE-AC05-76RL01830
}

Printed in the United States of America
Available to DOE and DOE contractors from the Office of Scientific and Technical Information,
P.O. Box 62, Oak Ridge, TN 37831-0062;
ph: (865) 576-8401
fax: $(865)$ 576-5728
email: reports@adonis.osti.gov

\begin{abstract}
Available to the public from the National Technical Information Service, U.S. Department of Commerce, 5285 Port Royal Rd., Springfield, VA 22161 ph: (800) 553-6847 fax: $(703) 605-6900$ email: orders@ntis.fedworld.gov online ordering: http://www.ntis.gov/ordering.htm
\end{abstract}

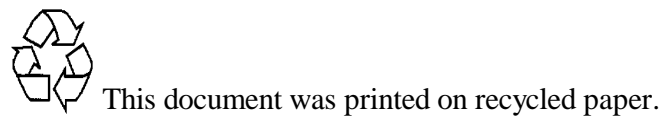




\section{PNNL OS3700 Tritium Monitoring System Software and Hardware Operations Manual Rev. 0}
JM Barnett
DM Carrell
DJ Duchsherer
DD Douglas
DR Sisk
GL Carter

November 2005

Prepared for the U.S. Department of Energy under Contract DE-AC05-76RL01830 


\section{Summary}

The PNNL OS3700 Tritium Monitoring System Software and Hardware Operations Manual describes herein how to install and operate the software and hardware on a personal computer in conjunction with the Berthold LB110 flow-through proportional counter detector system. Included are operational details for the software functions, how to read and use the drop-down menus, how to understand readings and calculations, and how to access the database tables. 



\section{Acknowledgements}

The PNNL OS3700 Tritium Monitoring System and this manual are the result of tremendous commitment from the following staff members who have committed their time and effort to the development, programming, testing, and authoring of the software and/or this manual:

- $\quad$ Brad P. Atencio

- J. Matthew Barnett

- $\quad$ Brad C. Barfuss

- Dorothy M. Carrell

- Greg L. Carter

- David D. Douglas

- Cheryl J. Duchsherer

- Daniel L. Edwards

- Michelle L. Johnson

- Daniel R. Sisk

- Edward Stapleton 



\section{Contents}

Summary.

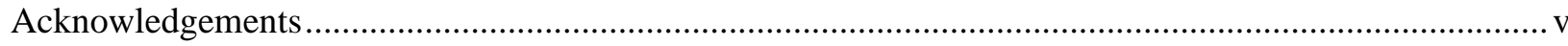

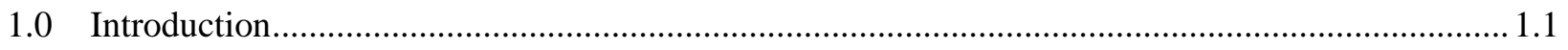

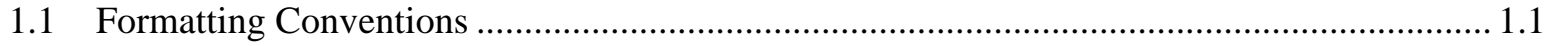

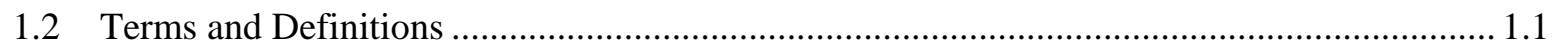

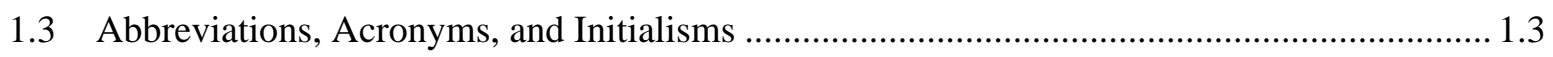

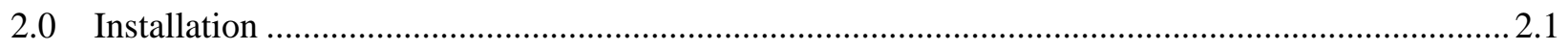

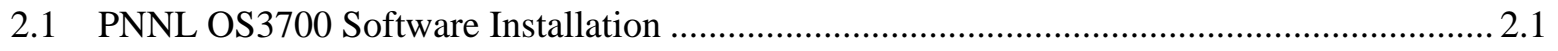

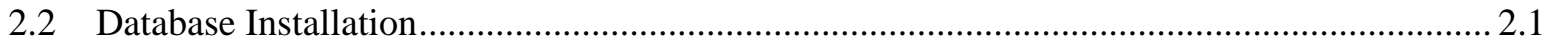

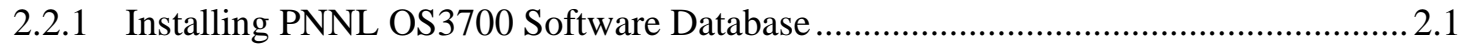

2.2.2 Uninstalling PNNL OS3700 Software ..................................................................... 2.1

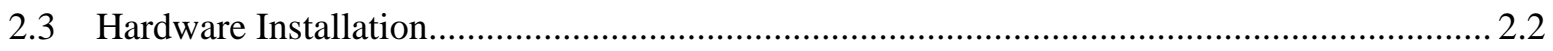

2.3.1 LabMaster ${ }^{\mathrm{TM}}$ Card Installation............................................................................... 2.2

2.3.2 LabMaster ${ }^{\mathrm{TM}}$ Card and Breakout Box Cable Connections ....................................... 2.2.2

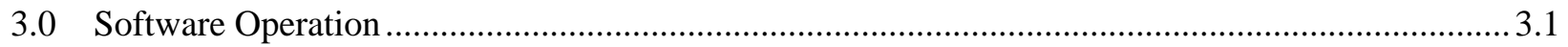

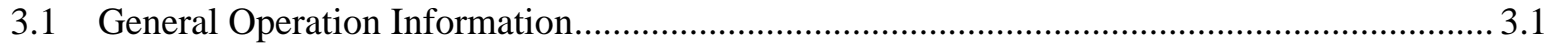

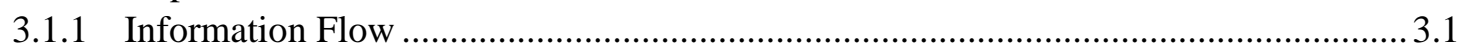

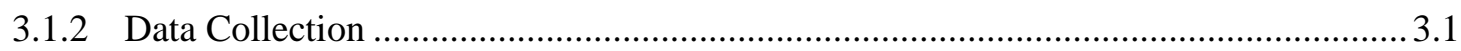

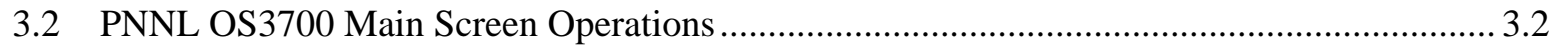

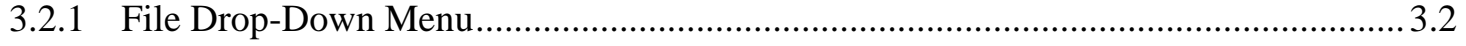

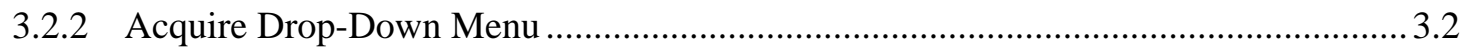

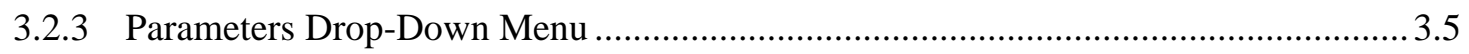

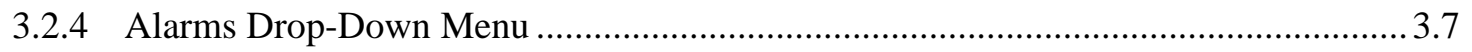

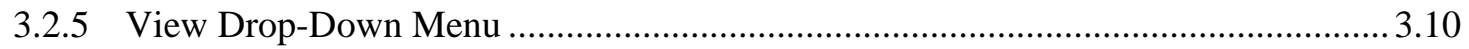

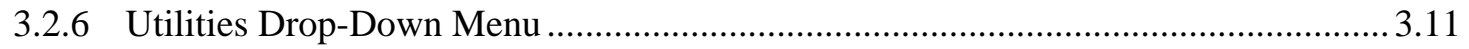

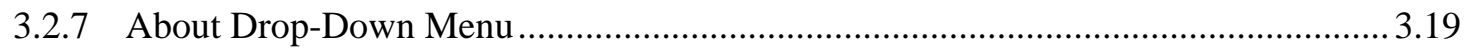

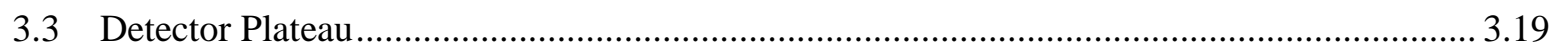

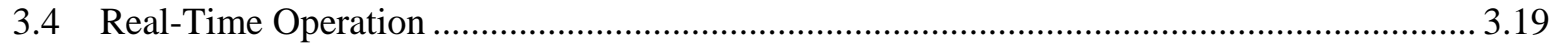

3.4.1 Strip-Chart Display and Elapsed Interactive Display …...........................................2.

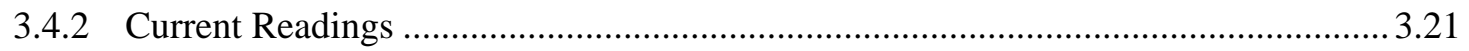

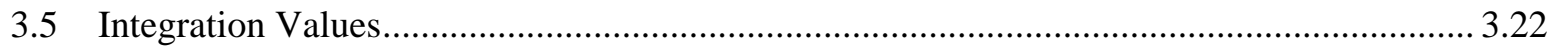

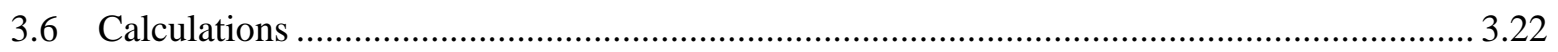

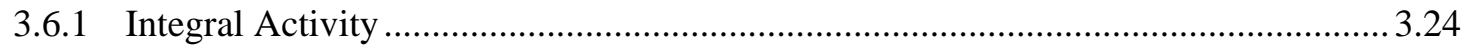

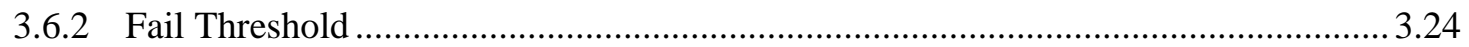




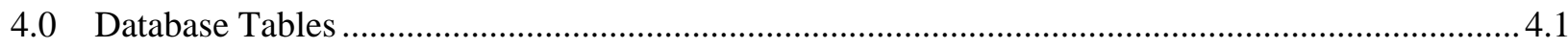

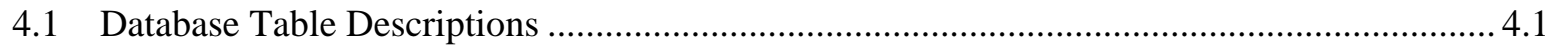

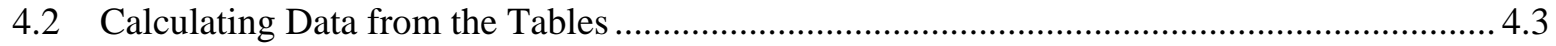

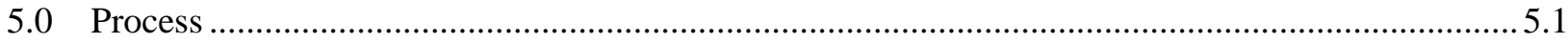

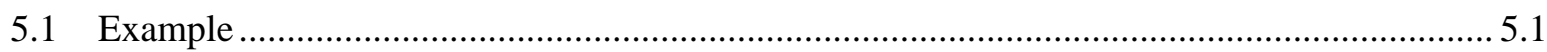

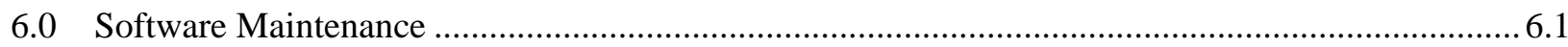

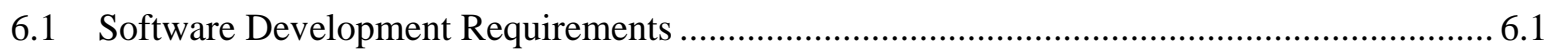

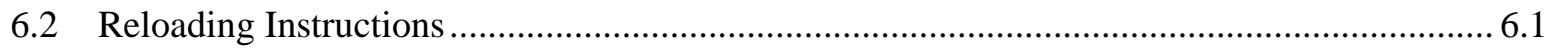

6.3 Maintenance Schedules and Procedures …............................................................................ 6.2

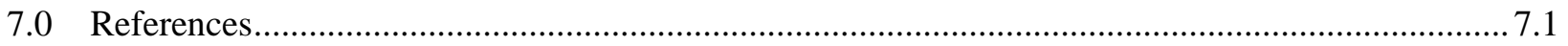

\section{Figures}

Figure 3.1. PNNL OS3700 Software Main Screen Menu.....................................................................3

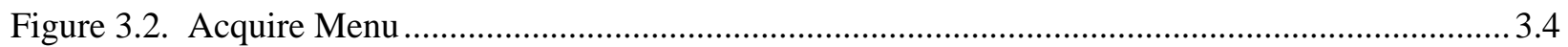

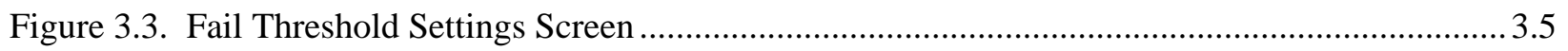

Figure 3.4. Preferences/Source Parameters Dialogue Box ............................................................. 3.6

Figure 3.5. Database Selection Dialogue Box ….......................................................................... 3.7

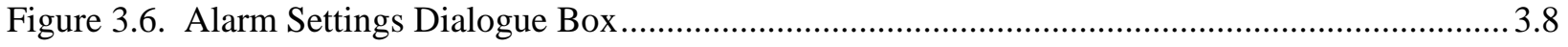

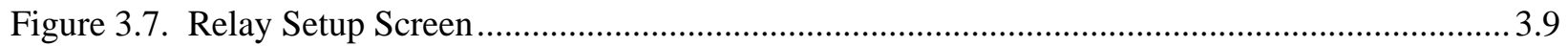

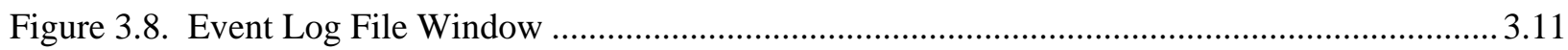

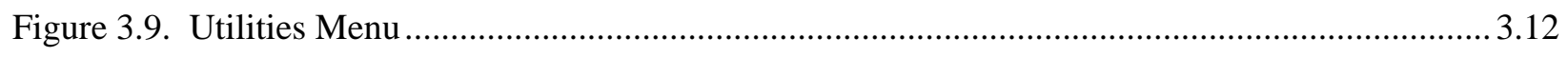

Figure 3.10. Preset Count Times Dialogue Box ........................................................................... 3.12

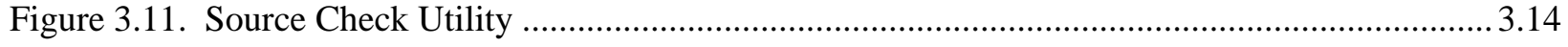

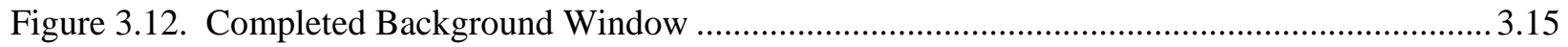

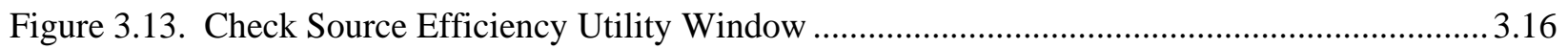

Figure 3.14. Tritium Efficiency Measurement Source Concentration Entry Window .......................... 3.17

Figure 3.15. Channel B Efficiency Manual Entry Window …............................................................ 3.18

Figure 3.16. Channel B Efficiency Store Values Window …...............................................................18

Figure 3.17. Main Real-Time, Interactive Graph Window …...............................................................2.20

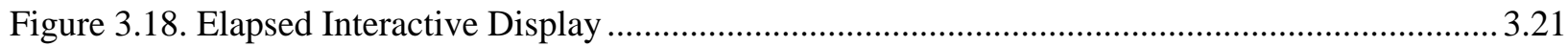

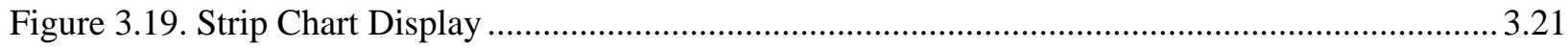




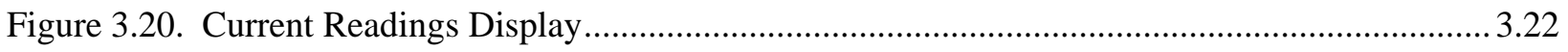

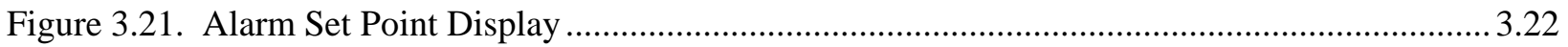

Figure 3.22. Integration Values Recored Every Long Count.......................................................... 3.22

\section{Tables}

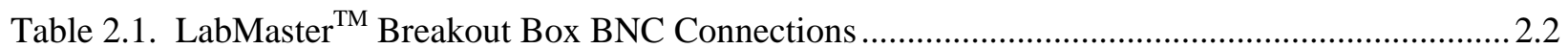

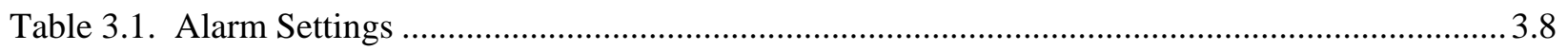

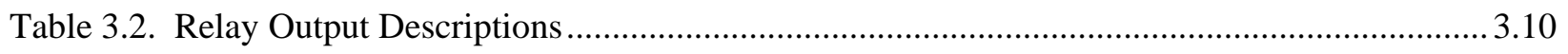

Table 4.1. Tables in the PNNL OS3700 Software Database …............................................................. 4.1

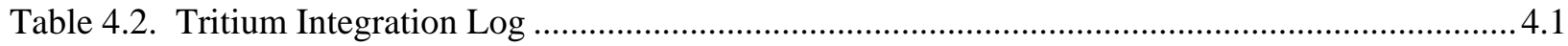

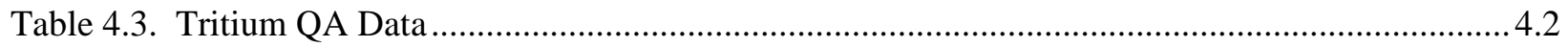

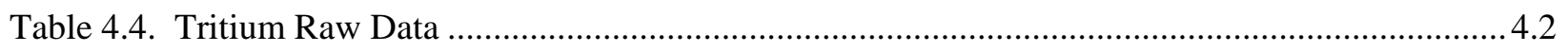

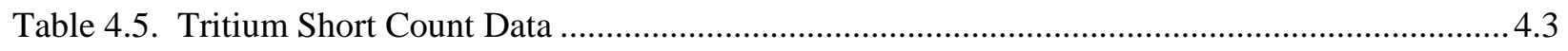

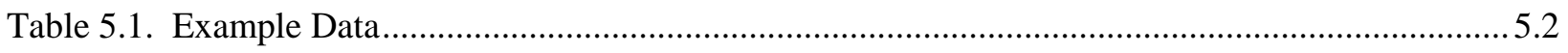

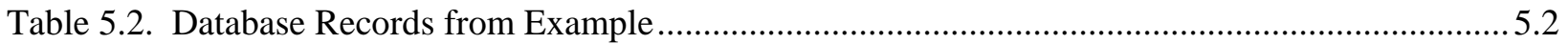

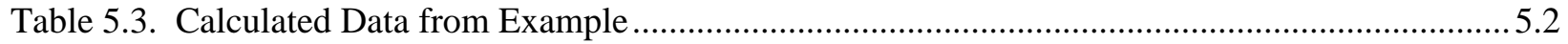

Table 5.4. Tritium Short Count Data Table Results from Example...................................................... 5.2

Table 5.5. Tritium Raw Data Table Results from Example.................................................................. 5.2

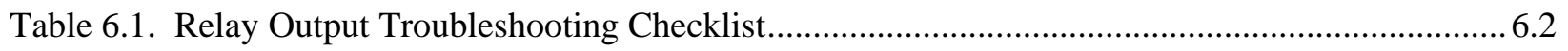




\subsection{Introduction}

The tritium stack monitoring system is controlled by a personal computer (PC) and measures tritium concentration in real time. It consists of the data acquisition system (OS3700 software) designed solely for use with the Berthold LB110 flow-through proportional counter detector system, a pump, and the detector system. The software and the associated acquisition electronics are not intended for use with any other instrument. This manual describes how to install and operate the Pacific Northwest National Laboratory (PNNL) OS3700 Tritium Monitoring System (PNNL OS3700) and use the software. For details on the LB110 detector, its maintenance, and its calibration procedure, refer to the hardware manual that accompanies the LB110.

\subsection{Formatting Conventions}

Software menus are bolded in this manual. The words Menu 1|Menu 2 are used to tell the user to select Menu 1 and then, from a drop-down menu, select Menu 2. Clickable buttons and field names on screens are in italics. Text in message boxes, such as "Enter your name," is surrounded by quotation marks.

\subsection{Terms and Definitions}

background

breakout box

Channel B

continuous air monitor

database

efficiency
The count rate of either channel (Tritium Channel or Channel B) in the LB110 caused by naturally occurring radioactivity of consistent materials, ambient air surrounding the detector, or components of cosmic radiation.

Connector box used to route signals from external instruments (such as the LB110) to the LabMaster ${ }^{\mathrm{TM}}$ card through a 68-pin connector and cabling. It also contains a power supply and universal relay circuit board that is used to drive external alarm relays.

The second of the two channels in the LB110 usually sets up as a background channel for the detection system. Note: See the term "Tritium Channel" for a definition for the first channel.

An instrument that continuously samples and measures the levels of airborne radioactive material in "real time" and has alarm capabilities at preset levels.

Note: The term continuous air monitor (CAM) is used in this manual to indicate the entire detection system.

Microsoft Access ${ }^{\circledR}$ database file where the PNNL OS3700 data are stored.

The count rate per known unit activity input into either channel of the LB110, usually measured as a fraction (e.g., 0.55) or a percentage (e.g., $55 \%)$. 
integral activity

LabMaster $^{\mathrm{TM}}$

LB110

long count time

PC

QA

rolling average

sample flow rate

stack flow rate

short count time

Tritium Channel

totalizer
The activity released during the 24-hr period beginning at midnight each day.

An ORTEC ${ }^{\circledR}$ multi-function data acquisition input/output PC card, which includes the counter/timers for collecting data from the LB150D and LB110 detectors.

Berthold-built gas flow-through proportional counter to detect and quantify tritium and other gases in air streams.

The period of time, set by the user, over which data from the LB110 are integrated. The long count time must always be an integral number of short count times (between 2 and 200).

Typically, the personal computer on which the PNNL OS3700 software is loaded.

Quality assurance (QA) information relating to the PNNL OS3700 detection system. The QA data are logged to the database Tritium97 in the table QATable and contain records of measurements such as efficiency, background, and the date the measurements were run.

A user-selected function in the Utilities menu, Count Times subheading of the software that allows the user to check alarms based on a rolling average of previous readings. The number of points to average is also selectable. When a new short count is obtained, the oldest short count of the averaging period is discarded and the average is recalculated.

Flow rate of air through the LB110 detector system. This is a fixed value and is set according to the procedure in the LB110 hardware manual.

Flow rate of the stack gases sampled by the LB110 detector system.

A user-selected integral fraction of the long count time, which is used by the software to determine instantaneous alarm rate conditions. Typically, one long count time equals six short count times. Note: The alarms are triggered by activity of the short count interval or on selectable running average if the user selects this option from the Utilities menu, Count Times subheading.

The first of the two channels in the LB110 detector system where counts for tritium pulses are collected and sent to the data acquisition electronics.

Flow total value for either the stack or sample flow rates equal to the flow rate times the integration period (e.g., $1 \mathrm{lpm} \times 60 \mathrm{~min}=601$ of totalized flow). 


\subsection{Abbreviations, Acronyms, and Initialisms}

$\begin{array}{ll}\text { BNC } & \text { Bayonet Neill Concelman - electrical cable connector } \\ \mathrm{Bq} & \text { Becquerel } \\ \mathrm{CAM} & \text { continuous air monitor } \\ \mathrm{CD} & \text { compact disc } \\ \mathrm{cfm} & \text { cubic feet per minute } \\ \mathrm{cm}^{3} & \text { cubic centimeter } \\ \mathrm{cpm} & \text { counts per minute } \\ \mathrm{cps} & \text { counts per second } \\ \mathrm{dps} & \text { disintegrations per second } \\ \mathrm{hr} & \text { hour } \\ 1 & \text { liter } \\ \mathrm{lpm} & \text { liters per minute } \\ \mathrm{M} & \text { micro } \\ \mu \mathrm{Ci} & \text { micro-curie } \\ \mu \mathrm{Ci} / \mathrm{l} & \text { micro-curie per liter } \\ \mu \mathrm{Ci} / \mathrm{ml} & \text { micro-curies per milliliter } \\ \mathrm{m}^{3} & \text { cubic meters } \\ \mathrm{MDA} & \text { minimum detectable activity } \\ \mathrm{min} & \text { minute } \\ \mathrm{PC} & \text { personal computer } \\ \mathrm{PNNL} & \text { Pacific Northwest National Laboratory } \\ \mathrm{PNNL} \text { OS3700 } & \text { PNNL OS3700 Tritium Monitoring System } \\ \text { QA } & \text { quality assurance } \\ \mathrm{S} / \mathrm{N} & \text { serial number } \\ \mathrm{V} & \text { volt } \\ \mathrm{yr} & \text { year } \\ & \end{array}$




\subsection{Installation}

The PNNL OS3700 software is designed to run on any PC using a 32-bit Windows $2000^{\circledR}$ Operating System. The PNNL OS3700 software also requires Microsoft Windows Access $97^{\circledR}$. The LabMaster ${ }^{\mathrm{TM}}$ data acquisition card and the tritium database need to be installed before software operation.

\subsection{PNNL OS3700 Software Installation}

To install the PNNL OS3700 software, follow the steps below.

1. Insert the compact disc (CD) into the CD drive of the computer (typically Drive $\mathrm{D}$ ).

2. From the Windows ${ }^{\circledR}$ Start menu, select Run.

3. Click the Browse button and change to the $\mathrm{CD}$ drive from the dialogue box.

4. Double-click the file named Setup.EXE.

5. After returning to the Run dialogue box, click $O K$, and the setup program will begin.

6. The software can be installed on any drive in any directory on the computer. Select the default drive and directory when prompted.

7. When complete, the program will indicate if the installation was successful.

Note: The computer does not need to be rebooted after installation is complete.

\subsection{Database Installation}

\subsubsection{Installing PNNL OS3700 Software Database}

After the PNNL OS3700 software is installed, the database for the tritium measurement data needs to be copied from the installation disk to the computer, as follows:

1. Create the C:IISEMSIISEMSDBS directory on the computer if not already on computer.

2. Insert the $\mathrm{CD}$ into the $\mathrm{CD}$ drive of the computer (typically Drive $\mathrm{D}$ ).

3. From the Windows ${ }^{\circledR}$ Start menu, select Programs|Windows Explorer.

4. Click on the $C D$ icon in the left-hand pane of the dialogue box.

5. Click the file named Tritium97.MDB in the right-hand pane of the dialogue box.

6. Copy the file from the CD (Edit|Copy menu) to the C:IISEMS IISEMSDBS directory.

7. Close Windows Explorer ${ }^{\circledR}$.

\subsubsection{Uninstalling PNNL OS3700 Software}

The PNNL OS3700 software can be uninstalled by using the "Add/Remove Programs" icon in the Windows ${ }^{\circledR}$ Control Panel. Select the PNNL OS3700 software from the list shown in the Control Panel. 
The database will not be automatically deleted when removing the software. If removal of the database is required, the operator must manually delete it from the computer using Windows Explorer ${ }^{\circledR}$.

\subsection{Hardware Installation}

\subsubsection{LabMaster ${ }^{\mathrm{TM}}$ Card Installation}

Before collecting data, the LabMaster ${ }^{\mathrm{TM}}$ data acquisition card must be installed in the PC. A detailed description of the installation procedure is in the LabMaster ${ }^{\mathrm{TM}}$ manual. To summarize:

1. Open the computer case (consult PC documentation).

2. Locate an available slot.

3. Remove the screw in the slot and the blanking panel from the PC (if installed).

4. Insert the LabMaster ${ }^{\mathrm{TM}}$ card firmly in the slot and reinsert the screw to hold the card in place.

\subsubsection{LabMaster ${ }^{\mathrm{TM}}$ Card and Breakout Box Cable Connections}

Connect the 68-pin ribbon cable between the LabMaster ${ }^{\mathrm{TM}}$ data acquisition card and the breakout box. This supplies the LabMaster ${ }^{\mathrm{TM}}$ card with easy-to-connect BNC, screw terminals, and 9-pin "D" connector for making the hardware connections.

The LabMaster ${ }^{\mathrm{TM}}$ breakout box has 24 BNC connectors on its front panel. For systems that use both the LB110 tritium CAM and the LB150D alpha/beta CAM, use the following connection scheme in Table 2.1 for the BNC connectors.

Table 2.1. LabMaster ${ }^{\mathrm{TM}}$ Breakout Box BNC Connections

\begin{tabular}{|c|l|l|}
\hline \hline Breakout Box & \multicolumn{1}{|c|}{ Signal } & \multicolumn{1}{c|}{ Description } \\
\hline 0 & LB150D Alpha & $\begin{array}{l}\text { Alpha Counter Output from Pseudo- } \\
\text { Coincidence Board }\end{array}$ \\
\hline 1 & LB150D Beta & $\begin{array}{l}\text { Beta Counter Output from Pseudo- } \\
\text { Coincidence Board }\end{array}$ \\
\hline 2 & $\begin{array}{l}\text { LB150D Total } \\
\text { Coincidence }\end{array}$ & $\begin{array}{l}\text { Total Coincidence Counter Output from } \\
\text { Pseudo-Coincidence Board }\end{array}$ \\
\hline 3 & $\begin{array}{l}\text { LB150D Random } \\
\text { Coincidence }\end{array}$ & $\begin{array}{l}\text { Random Coincidence Counter Output } \\
\text { from Pseudo-Coincidence Board }\end{array}$ \\
\hline 4 & LB150D Guard & $\begin{array}{l}\text { Guard Counter Output from Pseudo- } \\
\text { Coincidence Board }\end{array}$ \\
\hline $5-7$ & Empty & $\begin{array}{l}\text { Tritium Counter Output from rear of } \\
\text { LB110 }\end{array}$ \\
\hline 8 & LB110 Tritium & $\begin{array}{l}\text { Channel B Counter Output from rear of } \\
\text { LB110 }\end{array}$ \\
\hline 9 & LB110 Channel B & \multicolumn{2}{|l}{} \\
\hline
\end{tabular}




\subsection{Software Operation}

The software for the PNNL OS3700 provides several functions. These functions are:

- Set the information flow.

- Collect data at regular intervals.

- Store results in a database.

- Display the data collected.

- Run calibration and source test utilities.

Each function is discussed in the following sections.

\subsection{General Operation Information}

\subsubsection{Information Flow}

In very general terms, the LB110 detector collects pulses and stores them to one of two channels: Tritium Channel or Channel B. The pulse height discriminator circuits determine in which channel the counts will be stored based on their rise time. The signals from these two channels are sent through BNC cables from the detectors to the breakout box and then to the LabMaster ${ }^{\mathrm{TM}}$ data acquisition card through a 68-pin cable. The LabMaster ${ }^{\mathrm{TM}}$ card contains groups of counters and associated timers. When instructed by the software, a group of counters will collect the number of pulses from the LB110 over a period of time equal to the user-selected short count time.

After each short count period has expired, the PNNL OS3700 software requests the time and number of counts from the LabMaster ${ }^{\mathrm{TM}}$ card, increases the count time by one short time interval, and restarts the measurement process. The software uses the counts and time values from the LabMaster ${ }^{\mathrm{TM}}$ card to calculate the concentration of radiation from the Tritium Channel and Channel B during the count period and adds that to the running total. This process is repeated until a long count time is reached. After each long count time, the software stores the values of concentration and activity to a database along with other relevant information (such as the raw counts from the LabMaster ${ }^{\mathrm{TM}}$ card).

During each short count time, the software checks the concentration value against the alarm limit. If the alarm limit is exceeded, the software automatically changes the long count time to the short count time for faster data integration. Upon returning to a non-alarm state, the long count time is returned to the userdefined value. Optionally, during the short count time, the raw and calculated data can be stored in a separate database table for reconstructing each long measurement data set.

\subsubsection{Data Collection}

The software automatically retrieves data from the LabMaster ${ }^{\mathrm{TM}}$ card, calculates activities, and stores the data to the database file. The time period the LabMaster ${ }^{\mathrm{TM}}$ card is polled for status varies, depending on the current state of the software. When operating in normal mode (i.e., the status screen is on), the LabMaster $^{\mathrm{TM}}$ card is polled approximately every second (slightly longer when data need to be stored to the database). When a user is interacting with the software (changing parameters, etc.), the LabMaster ${ }^{\mathrm{TM}}$ 
card is polled approximately every 20 seconds. If the LabMaster ${ }^{\mathrm{TM}}$ card has completed a short counting period when the system makes a check, the following events occur:

- The data in the counters are read.

- The activity concentrations and totals are calculated.

- The calculated results are compared to alarm set points.

- The calculated results are populated in the Short Count Database (if option is enabled).

- If a long count time has been reached or the software detects an alarm, the counters are cleared, and the preset count time is set to one short count time interval.

- If a long count time has not been reached and the software does not detect an alarm condition, the count time in the LabMaster ${ }^{\mathrm{TM}}$ card is incremented by one short count time, and the process is repeated.

\subsection{PNNL OS3700 Main Screen Operations}

This section explains the menu functions of the PNNL OS3700 software. Note: Not all of these options will be available at all times (depending on whether data are being acquired). When the software is first started, the screen shown in Figure 3.1 is displayed.

\subsubsection{File Drop-Down Menu}

The following two options are available under the File menu:

- Print Setup allows you to set up the printer if one is connected to the computer.

- Exit closes the OS3700 program.

\subsubsection{Acquire Drop-Down Menu}

The options under the Acquire menu (Figure 3.2) are used to start and stop the tritium and other gas system counters (i.e., data acquisition). When the acquisition is stopped, the Utilities menu becomes available. The following options are available under the Acquire menu:

- Start

- Stop.

Only one button is enabled at a time: Stop when acquiring data, and Start when data acquisition is stopped. 
Tritium

File Acquire Parameters Alarms View Utilities About...

\section{ORTEC OS3700 Tritium-in-air Monitor}

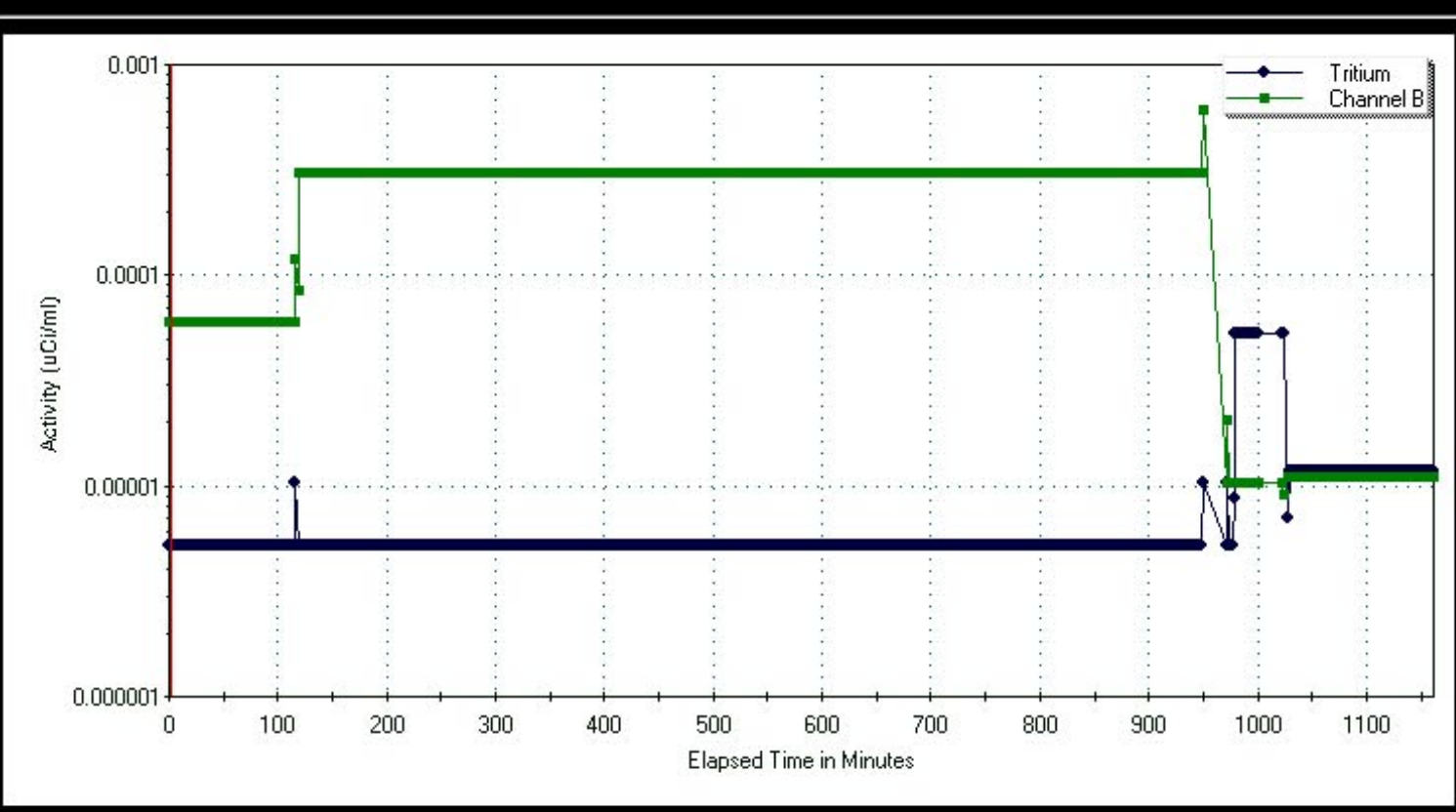

Raw Tritium CPS

Raw Ch B CPS: $\quad 1.5$
Alarm Setpoints

$\begin{array}{rlr}\text { Tritium: } & 1.98 \mathrm{E}-06 \\ \text { Channel B: } & 6.22 \mathrm{E}-06 \\ & \end{array}$

Current Readings -

Tritium: $\quad-5.20 \mathrm{E}-06 \mathrm{uCi} / \mathrm{ml}$

Chan B: $\quad-6.01 \mathrm{E}-05 \mathrm{uCi} / \mathrm{ml}$

Long Count 2 min

Short Count $\lcm{1} \min$

Integration Values

Tritium: $\quad-2.37 \mathrm{E}+06$

Chan B: $\quad-2.74 E+07$ uC

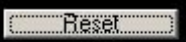

\begin{tabular}{|c|c|}
\hline $\begin{array}{l}\text { Tritium: } \\
\text { Chan B: }\end{array}$ & Zoom \\
\hline Chan B: & $\begin{array}{l}\text { Point } \\
\text { Restore }\end{array}$ \\
\hline
\end{tabular}

Figure 3.1. PNNL OS3700 Software Main Screen Menu 


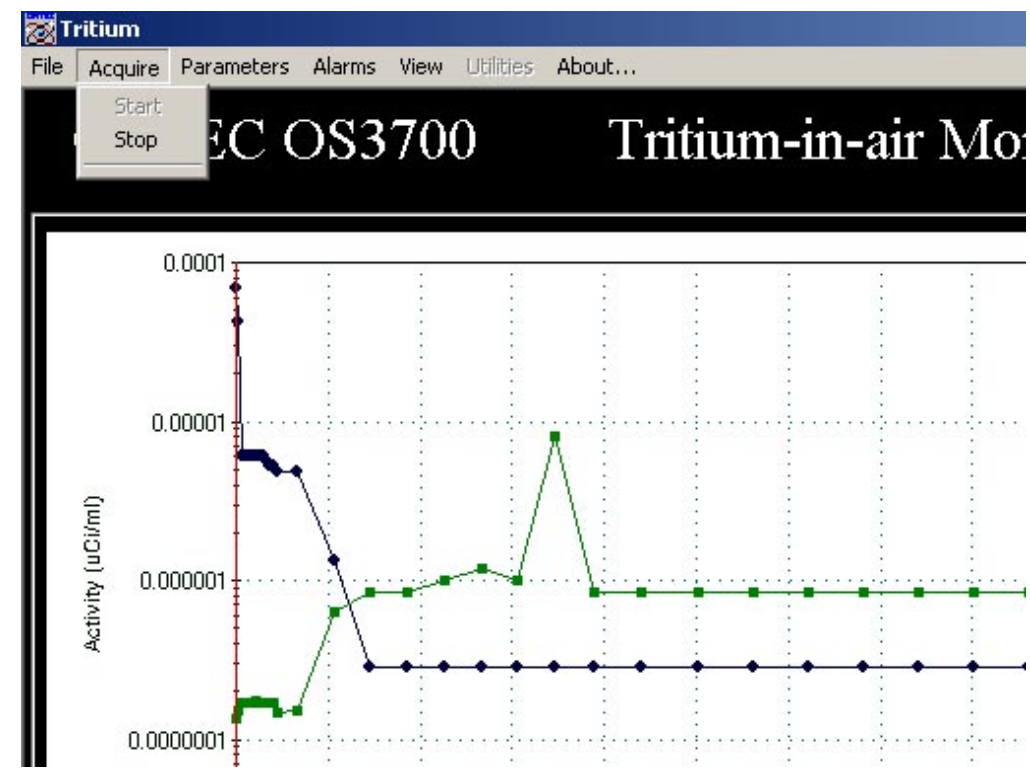

Figure 3.2. Acquire Menu

\subsubsection{Start}

The Start menu starts the routine data collection from the LB110. The real-time display and data acquisition can be stopped by clicking on Acquire|Stop. If data are being actively collected, the software will warn the operator that closing the real-time display will terminate the current counting and offer the option to cancel this operation.

\subsubsection{Stop}

When the Stop option is selected, the data from the LB110 detector system are retrieved from the LabMaster ${ }^{\mathrm{TM}}$ card, calculated, and stored to the database. To restart the counting, the operator must select Start from the Acquire menu. The counting status is provided on the bottom-left corner of the display screen. In the stopped mode, the Utilities menu is available, and the count time can be set. To restart data acquisition, select the Acquire|Start menu.

Note: The stack monitoring system computer is equipped with a commercial hardware/software monitoring system called Watchdog. Watchdog monitors both PNNL OS3700 and PNNL OS3300 stack monitoring software for system lockups by verifying that timestamps on the database files are updated. If either software program does not successfully provide a new record in a specified amount of time, Watchdog assumes the system has locked up and executes a hard reboot of the system. All necessary programs are maintained in the startup menu, so the reboot will restart all necessary stack monitoring programs.

Note: Since Watchdog triggers on unsuccessful database entries from the software, pause Watchdog before stopping the counting process. Once the interface with PNNL OS3700 is complete, Watchdog will need to be restarted.

Note: Watchdog has an active icon (shaped like a human heart) that will palpitate when the program is running. The icon is located in the bottom right-hand corner of the computer screen in the system tray. 
By clicking on the icon, an interactive window will appear where the program can be paused and or resumed.

\subsubsection{Parameters Drop-Down Menu}

Parameters for the software can be set from the main window under the Parameters menu. The options under the Parameters menu are used to set the operating options and values for the program. The following options are available under the Parameters menu:

- $\quad$ Fail Threshold

- Preferences

- Select Database.

\subsubsection{Fail Threshold}

The fail threshold setting is an alarm value that determines whether a particular channel of the measuring system is functioning properly. The values input into these boxes (Figure 3.3) represent the MINIMUM values that must be obtained by the electronics to demonstrate the systems are functioning. A failure to meet these count levels will result in a CAM Function alarm as well as a Fail Threshold alarm in the offending channel.

The factory defaults are zero cpm for both channels. Setting these values too high may result in false alarms of the CAM Function. The count time is fixed and equal to the short count measuring time. The fail threshold is checked after every short count measuring time.

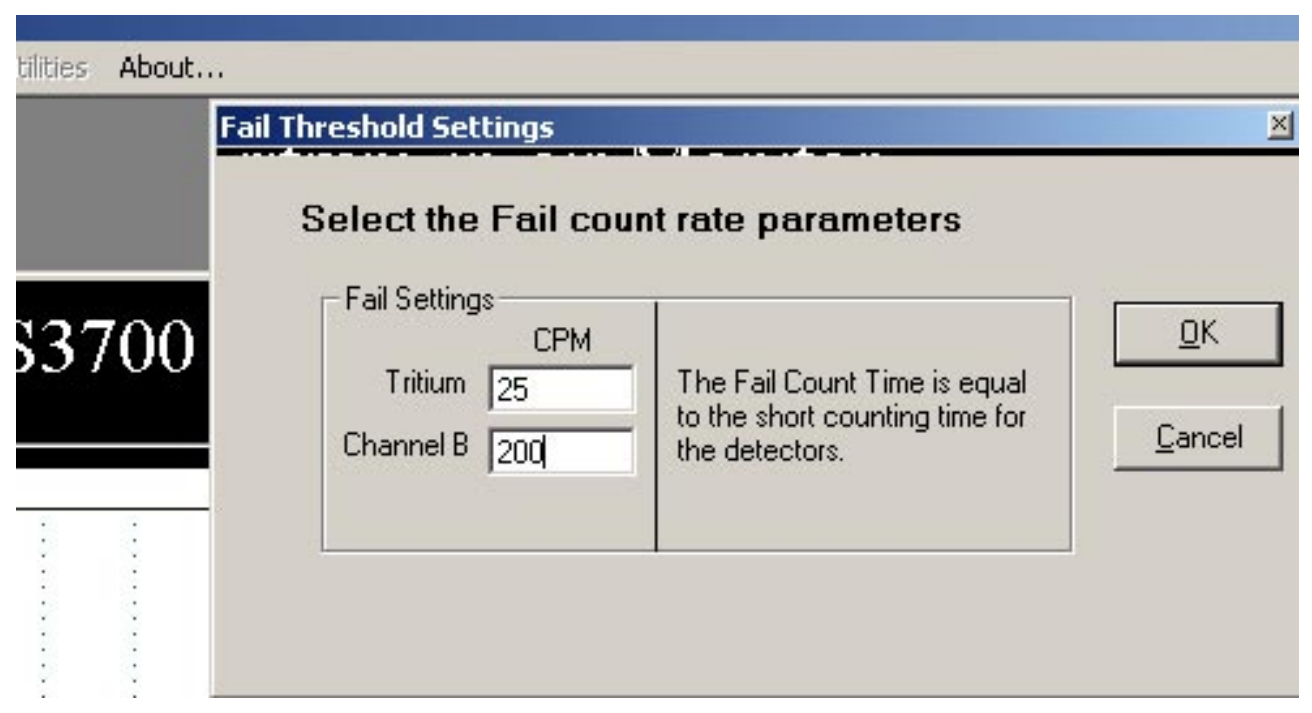

Figure 3.3. Fail Threshold Settings Screen

\subsubsection{Preferences}

The Preferences menu allows the operator to set certain values for the PNNL OS3700 software. The dialogue box (Figure 3.4) is displayed when the Preferences menu is selected. 


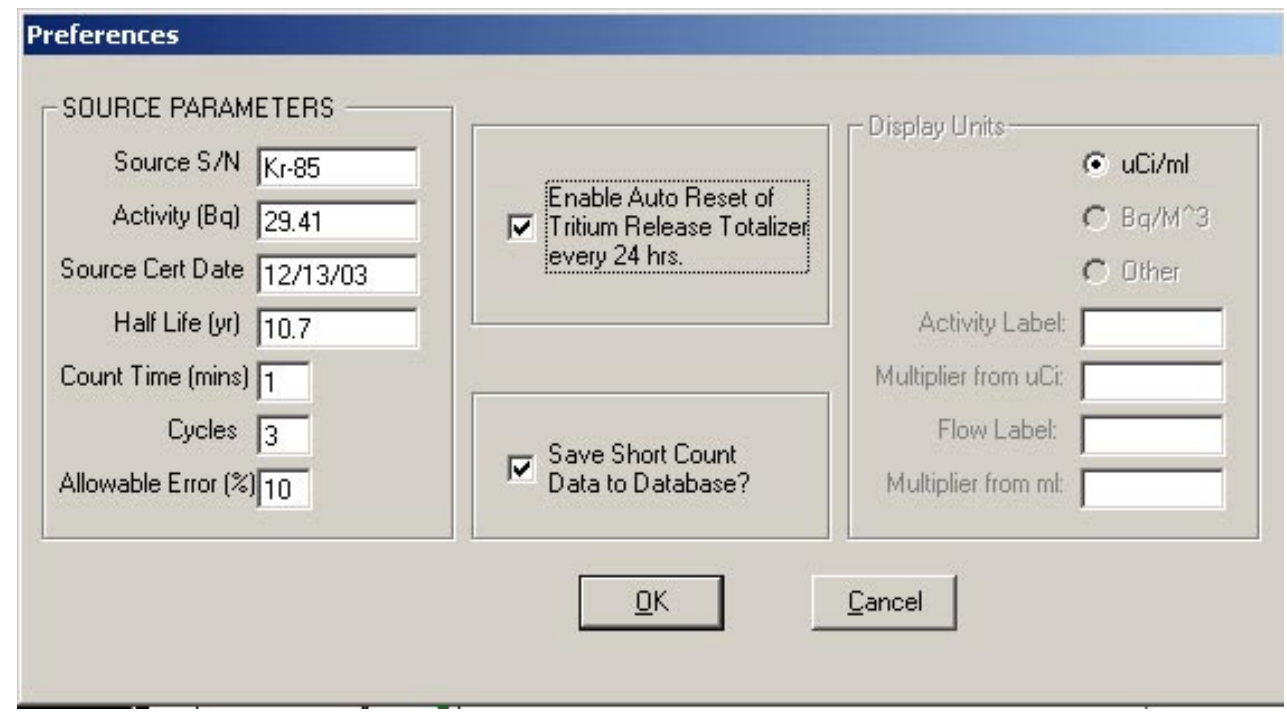

Figure 3.4. Preferences/Source Parameters Dialogue Box

The available selections and settings are described below.

- Source $S / N$ : The serial numbers of the sources used to perform source checks should be entered into this field. This field allows any alpha-numeric naming convention to designate the tritium source used in Source Check and efficiency utilities.

- Activity (Bq): The activity, in Becquerels $(\mathrm{Bq})$, associated with the tritium/krypton Source Check run.

- Source Cert Date: The date the source activity was certified is entered in this field. The data must be entered in the form mm/dd/yyyy. The source activity is decay corrected (by the software) from the source certification date to the date the source check is performed.

- Half-Life (yr): In years, the half-life of the nuclide used for Source Check.

- Count Time (mins): When the Source Check utility is run, several counts are completed. The count time for each count is equal to the value entered in this field. The number of counts is set by the parameter Cycles. The detection efficiency reported when the Source Check utility finishes is the average detection efficiency for all cycles.

- Cycles: When the Source Check utility is run, several count cycles are completed. The number of count cycles is determined by the value entered in this field.

- Allowable Error \%: The percent set in this field applies to the Source Check pass or fail criteria.

- Enable Auto Reset: A check in this box causes the software to automatically reset the Tritium and Channel B total values every day at approximately midnight.

- Save Short Count Data to Database: When this box is checked, both long count and short count data are sent to the database, each in the applicable table. When it is unchecked, only the long count data are sent to the database. This setting can be used to manage the size of the database file.

- Display Units: This section, which is disabled in this software version, allows the operator to choose between $\mu \mathrm{Ci} / \mathrm{ml}$ and $\mathrm{Bq} / \mathrm{m}^{3}$ as standard display units or enter conversion factors for customized units. This does not affect the units where data are stored because those units are fixed. 


\subsubsection{Select Database}

Upon installation, the database name and path must be entered under "Select Database" so the program knows where to store the data (Figure 3.5). This option may also be used if the user changes the name of the database.

The software is initially set up to store data in an Access database titled, Tritium97.mdb. If the database is renamed, the user must use the Parameters|Select Database menu to direct the PNNL OS3700 software to the new database file location. The output database must have the same tables and fields as the one supplied with the original software.

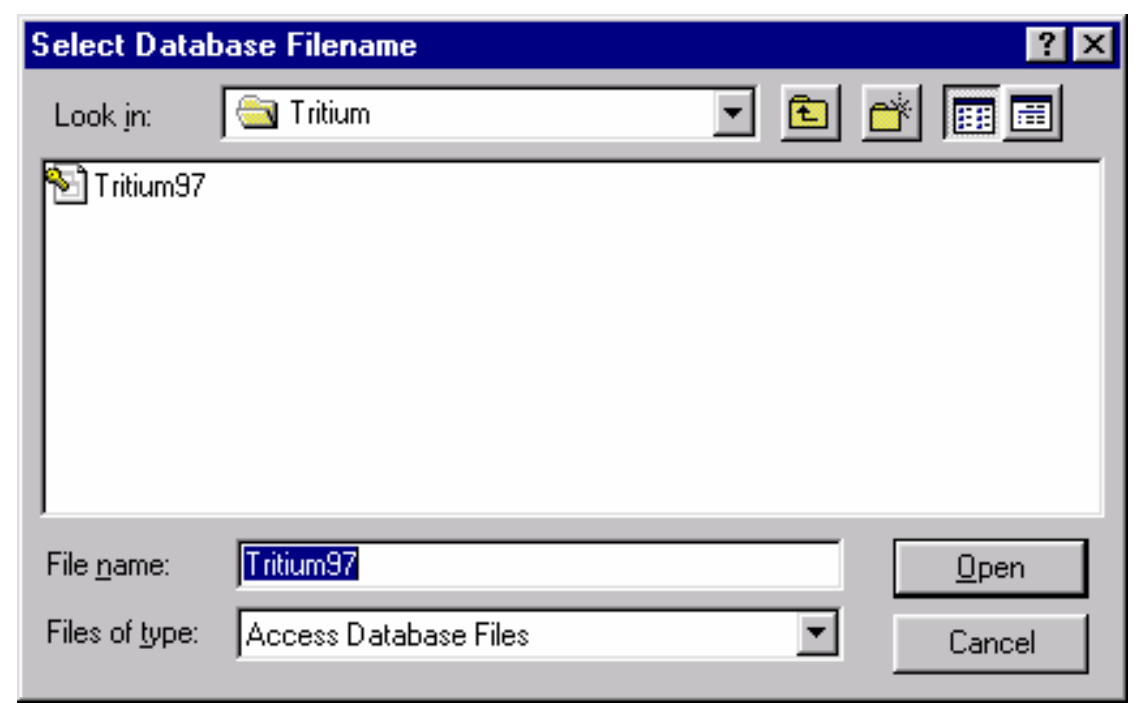

Figure 3.5. Database Selection Dialogue Box

\subsubsection{Alarms Drop-Down Menu}

The Alarms menu allows the user to configure the CAM alarms. The following options are available under the Alarms menu:

\section{- Settings}

- Relay Setup.

\subsubsection{Settings}

The Alarm|Settings menu brings up the dialogue box shown in Figure 3.6. The alarm values in this box should be filled in with the site-specific information required. Each of the items in this dialogue box is described in Table 3.1. Some alarm settings may not be enabled for specific software installations. These items will be grayed out as shown in Figure 3.6. 


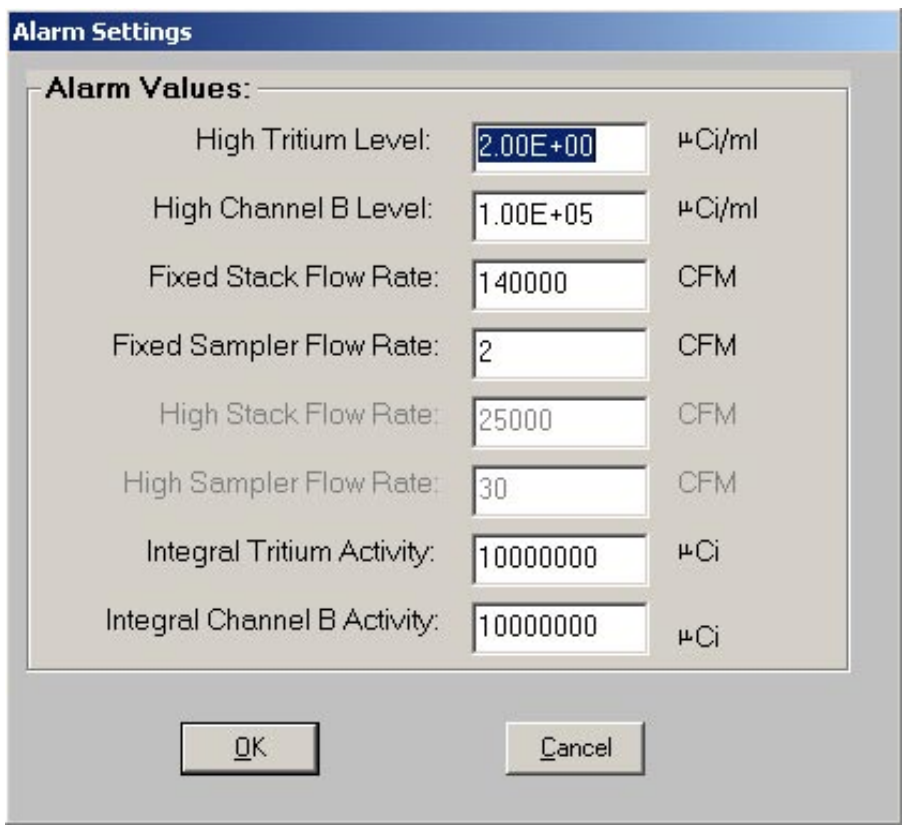

Figure 3.6. Alarm Settings Dialogue Box

Table 3.1. Alarm Settings

\begin{tabular}{|l|l|l||}
\hline \multicolumn{1}{|c|}{ Item } & \multicolumn{1}{|c|}{ Description } & Factory Default \\
\hline $\begin{array}{l}\text { High Tritium } \\
\text { Level }\end{array}$ & $\begin{array}{l}\text { Tritium activity concentration alarm value for either a } \\
\text { long or short count interval (in } \mu \mathrm{Ci} / \mathrm{ml})\end{array}$ & $1.00 \times 10^{-9} \mu \mathrm{Ci} / \mathrm{ml}$ \\
\hline $\begin{array}{l}\text { High Channel B } \\
\text { Level }\end{array}$ & $\begin{array}{l}\text { Channel B activity concentration alarm value for } \\
\text { either a long or short count interval (in } \mu \mathrm{Ci} / \mathrm{ml})\end{array}$ & $1.00 \times 10^{-9} \mu \mathrm{Ci} / \mathrm{ml}$ \\
\hline $\begin{array}{l}\text { Fixed Stack } \\
\text { Flow Rate }\end{array}$ & $\begin{array}{l}\text { Flow rate for fixed flow stack systems. This value is } \\
\text { used to calculate the flow total through the stack for } \\
\text { any given integration period. }\end{array}$ & $1000 \mathrm{~m}^{3}$ \\
\hline $\begin{array}{l}\text { Fixed Sampler } \\
\text { Flow Rate }\end{array}$ & $\begin{array}{l}\text { Set by site-specific requirements and measurements. } \\
\text { See the LB110 manual for more information. }\end{array}$ & 2 \\
\hline $\begin{array}{l}\text { Hi Stack Flow } \\
\text { Rate }\end{array}$ & $\begin{array}{l}\text { Not used by the PNNL OS3700 software since this } \\
\text { alarm is generated directly by the LB110 or by other } \\
\text { instruments independent of the CAM }\end{array}$ & $25,000 \mathrm{~m}^{3}$ \\
\hline $\begin{array}{l}\text { Hi Sampler } \\
\text { Flow Rate }\end{array}$ & $\begin{array}{l}\text { Not used by the PNNL OS3700 software since this } \\
\text { alarm is generated directly by the LB110 sample flow } \\
\text { rate control module }\end{array}$ & $\mathrm{N} / \mathrm{A}$ \\
\hline $\begin{array}{l}\text { Integral Tritium } \\
\text { Activity }\end{array}$ & $\begin{array}{l}\text { Tritium activity alarm level for total tritium output } \\
\text { through the stack }\end{array}$ & $0.001 \mu \mathrm{Ci}$ \\
\hline $\begin{array}{l}\text { Integral Channel } \\
\text { B Activity }\end{array}$ & $\begin{array}{l}\text { Channel B activity alarm level for total activity output } \\
\text { through the stack }\end{array}$ & $0.001 \mu \mathrm{Ci}$ \\
\hline \hline
\end{tabular}




\subsubsection{Relay Setup}

The Alarm|Relay setup menu allows the operator to define the relay configuration for the PNNL OS3700 software. Any alarm threshold that is exceeded can generate an alarm output. The operator uses the Relay Setup screen (Figure 3.7) to set alarms associated with the digital output from the LabMaster ${ }^{\mathrm{TM}}$ card or relays. More than one alarm can be output to any LabMaster ${ }^{\mathrm{TM}}$ channel (with six channels available). The software uses a logical "OR" function to determine whether an output is generated. For instance, in Figure 3.7, if either the CAM Function alarm occurs or the Tritium Fail Threshold is not met, the relay output \#1 is activated.

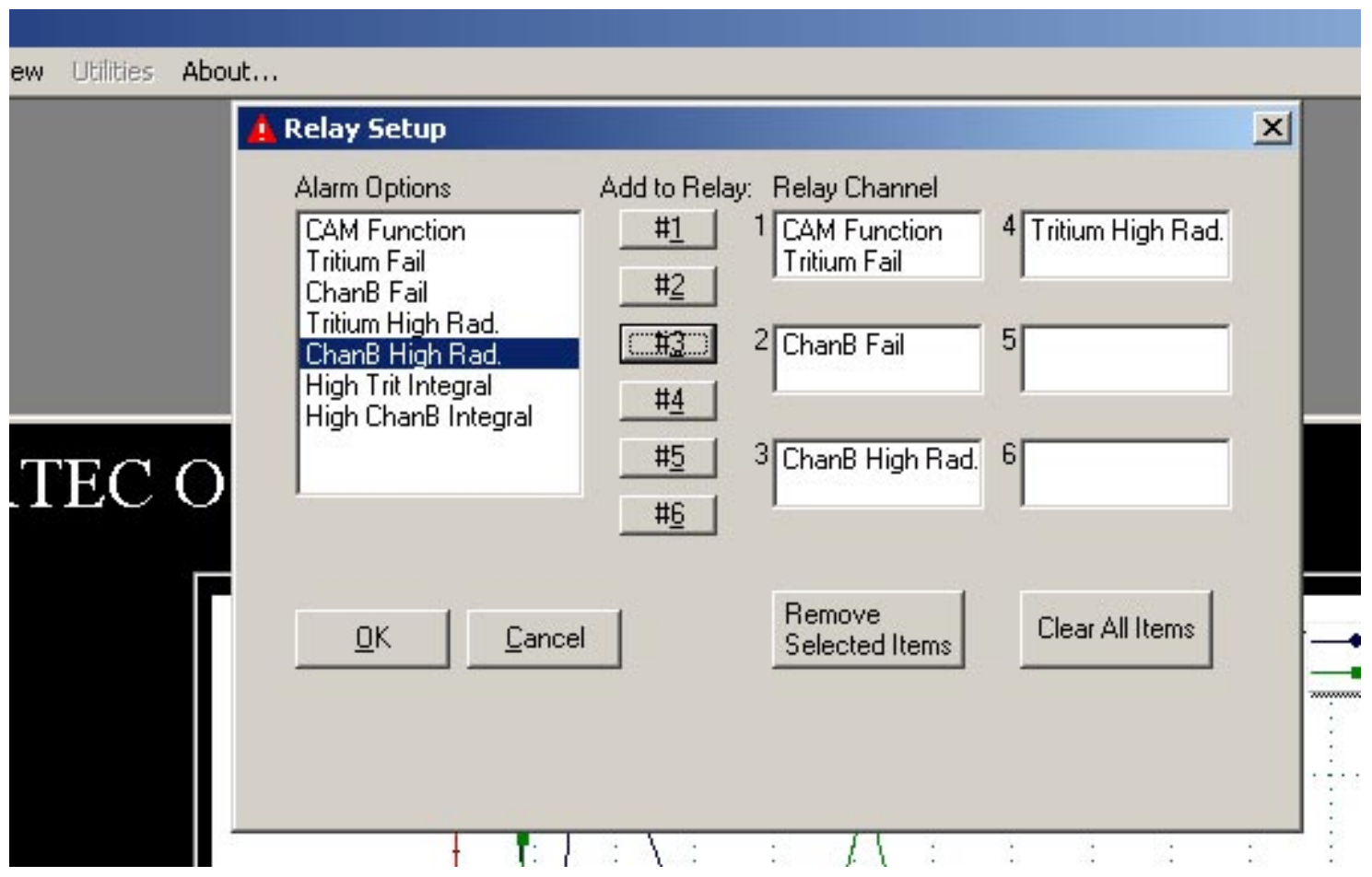

Figure 3.7. Relay Setup Screen

To add a function to a relay, click on one of the Alarm Options in the left-hand list and click the numbered button in the middle of the screen to add it to the appropriate relay channel. Each function can be set to any number of relays simultaneously. To remove a specific item from a relay, click on that item in the relay channel box and click the Remove Selected Items button. All other functions and relays will remain unchanged. To delete all the functions from all the relays, click the Clear All Items button. Different alarm options are available on different installations (depending on other equipment and/or services purchased with the system). The relay functions are described in Table 3.2. 
Table 3.2. Relay Output Descriptions

\begin{tabular}{|l|l||}
\hline \multicolumn{1}{|c|}{ Function Name } & \multicolumn{1}{c|}{ Description } \\
\hline CAM Function & $\begin{array}{l}\text { An alarm that occurs when either the Tritium Channel or Channel B Fail } \\
\text { Threshold is not met. For example, in the setup shown in Figure 3.7, if } \\
\text { Channel B does not meet the fail threshold, both relay output 1 and relay } \\
\text { output 2 will be activated. }\end{array}$ \\
\hline Tritium Fail & $\begin{array}{l}\text { An alarm that occurs when the total number of counts in the tritium counter of } \\
\text { the LabMaster }{ }^{\mathrm{TM}} \text { card is less than the fail threshold value set in Section 3.2.3.1. }\end{array}$ \\
\hline ChanB Fail & $\begin{array}{l}\text { An alarm that occurs when the total number of counts in the Channel B counter } \\
\text { of the LabMaster } \\
\text { Section } 3.2 .3 .1 .\end{array}$ \\
\hline Tritium High Rad. & $\begin{array}{l}\text { An alarm that occurs when the calculated concentration of tritium activity for } \\
\text { either a short or long count interval exceeds the value set in Section 3.2.4.1. } \\
\text { or } \\
\text { The average concentration calculated using the rolling average is higher than } \\
\text { the value set following information in Section 3.2.4.1 if the rolling average } \\
\text { option is enabled. See Section 3.2.6.1 for instructions on enabling rolling } \\
\text { average. }\end{array}$ \\
\hline ChanB High Rad. & $\begin{array}{l}\text { An alarm that occurs when the calculated concentration of activity in } \\
\text { Channel B for either a short or long count interval exceeds the value set in } \\
\text { Section 3.2.4.1 } \\
\text { or } \\
\text { The average concentration calculated using the rolling average is higher than } \\
\text { the value set in Section 3.2.4.1 if the rolling average option is enabled. }\end{array}$ \\
\hline High Trit. Integral & $\begin{array}{l}\text { An alarm that occurs when the calculated integrated activity release of tritium } \\
\text { exceeds the value set in Section 3.2.4.1. }\end{array}$ \\
\hline $\begin{array}{l}\text { An alarm that occurs when the calculated integrated release of activity in } \\
\text { Channel B exceeds the value set in Section 3.2.4.1. }\end{array}$ \\
\hline
\end{tabular}

\subsubsection{View Drop-Down Menu}

The View menu is only used to access Event Files, which are created when an event occurs during normal data acquisition, such as an alarm or a failure.

The filename format is YYMMDD.log where

- YY are the last two digits of the year the file was created

- MM is the number corresponding to the month the data was created

- $\mathrm{DD}$ is the day the data was created.

Event Files opens a window from which the user can select an event file by date (Figure 3.8). The event $\log$ files contain information on:

- Dates and times for events

- Channel failures from low counts

- Alarms for Tritium Channel and Channel B High Concentration, High Rolling Average Concentration, and High Integral Activity 
- Actions taken such as "Setting Long Count time equal to Short Count time."

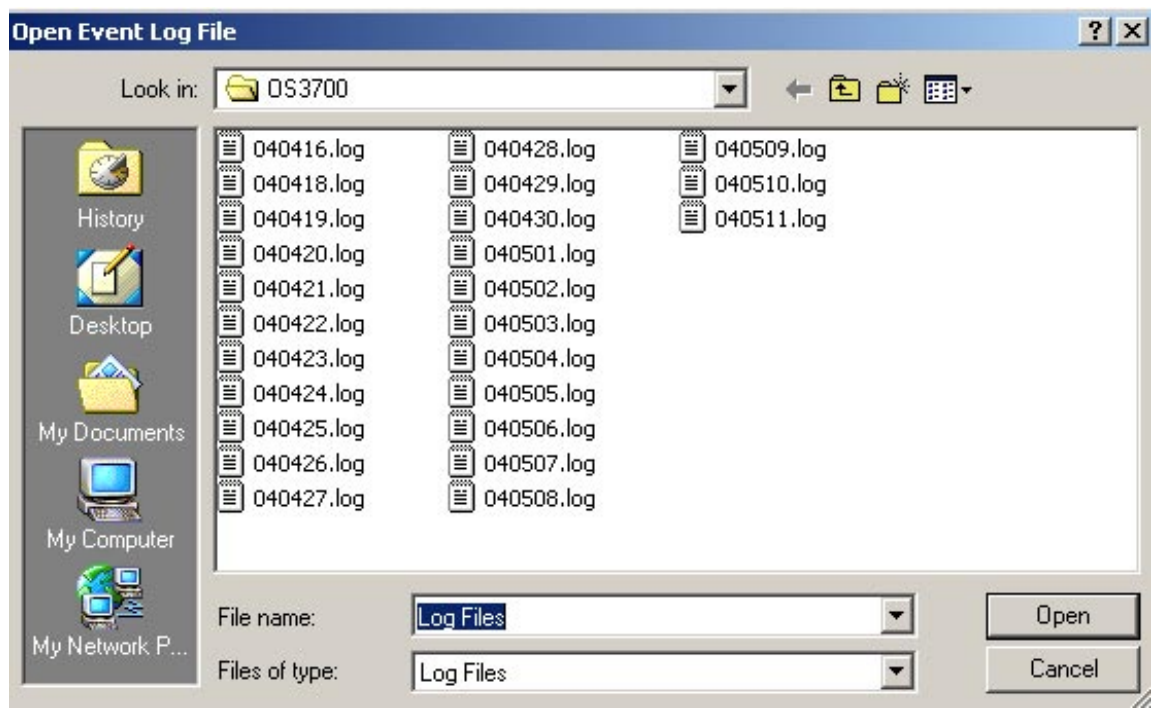

Figure 3.8. Event Log File Window

\subsubsection{Utilities Drop-Down Menu}

The Utilities menu is grayed out in the main acquisition screen, and Acquire|Stop must be selected before using the utilities. The PNNL OS3700 software has the following six utilities (Figure 3.9):

- Count Times

- Source Check

- Background

- Check Source Efficiency

- Tritium Efficiency

- Channel B Efficiency.

The calibration technician uses the Background, Check Source Efficiency, Tritium Efficiency, and Channel B Efficiency utilities to determine the values for the efficiencies and background measurements. Count Times and Rolling Average are set under the Utilities menu. For user reference, the values entered and determined with these utilities are stored in the QA database table. 


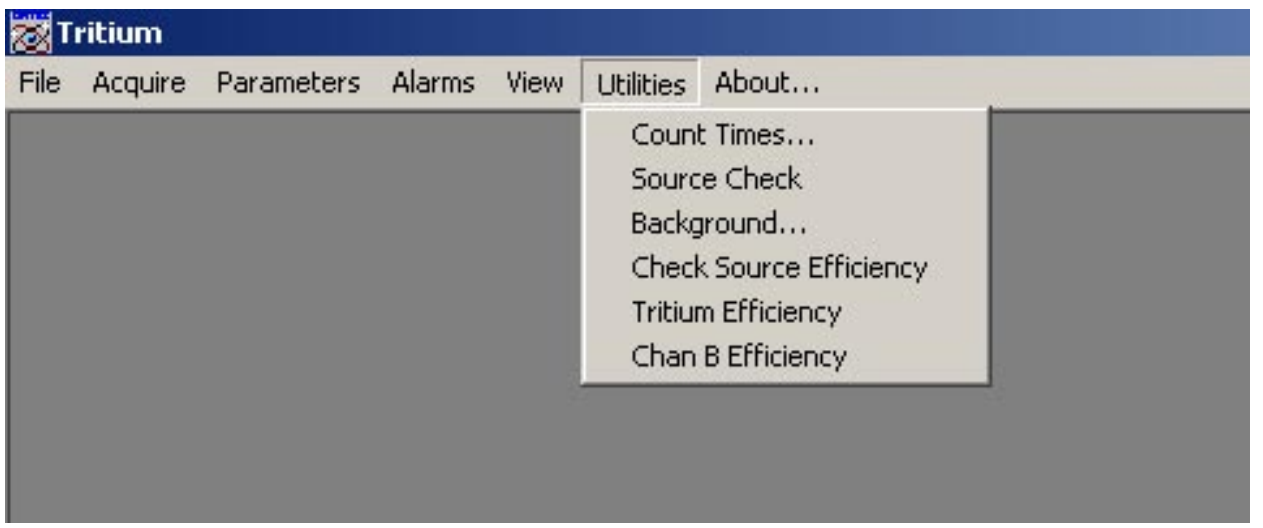

Figure 3.9. Utilities Menu

\subsubsection{Count Times}

The Count Times dialogue box is used to change the current short and long measuring times. When entering these times, the minimum allowable count time is 1 minute, the short count time must be less than or equal to the long count time, and the long count time must be an integer multiple of the short count time between 1 and 200. Figure 3.10 shows the Preset Count Times dialogue box.

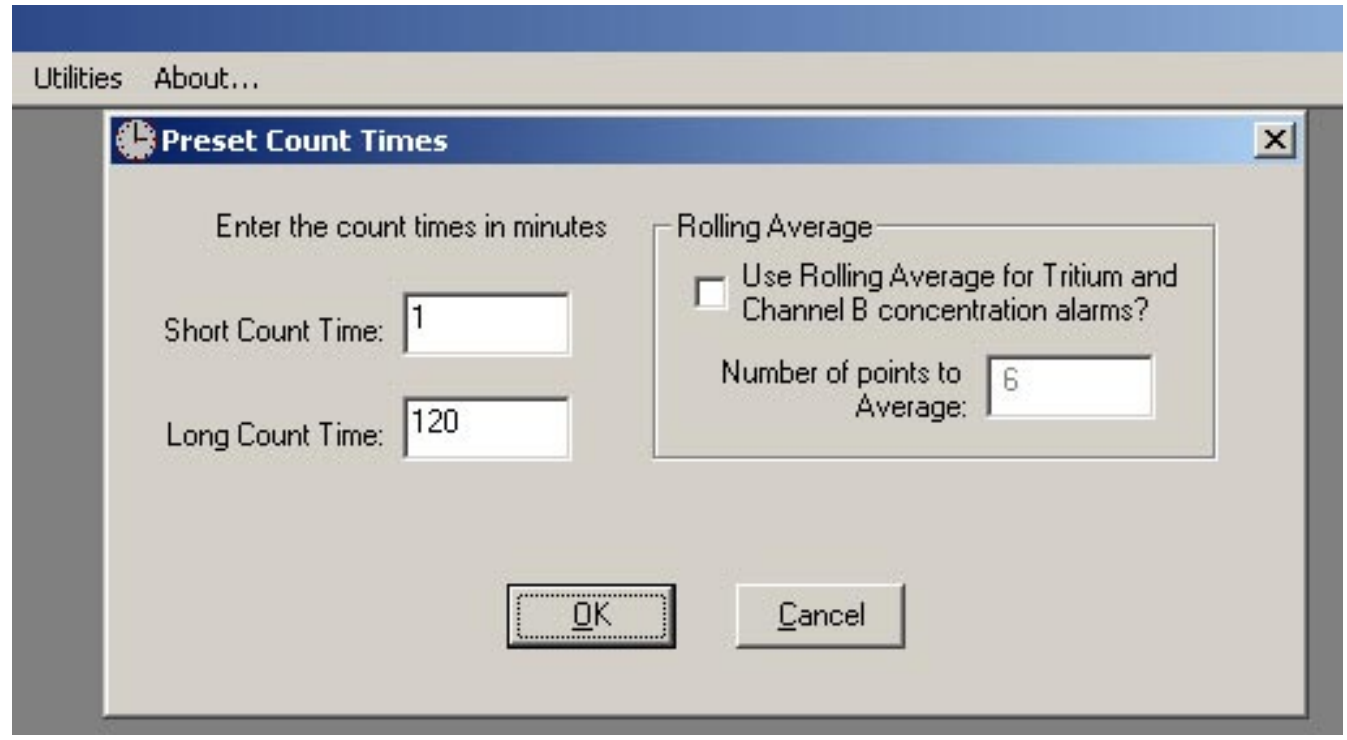

Figure 3.10. Preset Count Times Dialogue Box

After selecting the short count time, the computer will automatically suggest a long count time. This can be overridden if the user enters another valid entry. When two valid entries are made, after clicking on $O K$, the system stores these new values and immediately sends the new count times to the LabMaster ${ }^{\mathrm{TM}}$ card. Any data currently in the LabMaster ${ }^{\mathrm{TM}}$ card will be over-written. Selecting Cancel will cancel any changes made and restore the previous settings.

Rolling Average is used as an alternate way to determine the concentration alarms and is enabled by checking the box (Figure 3.10) in the Preset Count Times window. The number of points, or readings, to be averaged must be entered and must be equal to or less than 200 . 
The short count time is used to determine if a concentration alarm is being approached. The long count time is used to integrate the activity measurement for a particular volume of effluent. If any concentration alarm level is exceeded during a single short counting period, the long measuring time is changed to equal the short measuring time. This situation remains in effect until the concentration alarm clears.

The short count time is also used as the fail threshold count time. If the user-selected number of counts is not reached in the short count time for either channel, an alarm is generated.

\subsubsection{Source Check}

The Source Check utility can be used by the system operator to verify that the detector's efficiency still matches that found at the time of calibration. Parameters for this utility are found under the main menu Parameters|Preferences. The OS2700 system is designed to use a gas source with the Source Check utility. Normally, the Check Source efficiency would be found during the calibration and the system would be checked using the same gas source throughout the year.

When the Source Check utility is started, the user is prompted to enter his/her name. Any alphanumeric string may be entered. Entering a blank or clicking Cancel cancels the Source Check utility, and the program returns to the main screen.

After entering your name, select $O K$. A message box will display a pop-up warning for the operator to "Be sure to disconnect the tritium monitor from any stack or room air sampling equipment. Click $O K$ when ready to begin source check." Next, the operator is asked to confirm the source serial number and the source certified activities (the program will decay correct the source activities to the date the source check is performed). If correct, select OK. If incorrect, select Cancel and go to Parameters|Preferences to change source activities, certification dates, and serial numbers. Click $O K$ after placing the check source in the chamber. It is recommended to use the same source that is used when making check source efficiency measurements. The utility is started by selecting Start. The system will count the source for the number of cycles indicated by the settings made in the Preferences window.

At the end of each cycle, the counts per second (cps) and the calculated efficiency (per Equation 3.1) for the Tritium Channel and Channel B are displayed.

$$
\text { Tritium Eff } .=\frac{\text { Tritium }(\mathrm{cps})-[\text { Avg tritium Bkg }(\mathrm{cpm}) / 60]}{\text { Decay corrected tritium source activity }(\text { dps })}
$$

The count time for each cycle and the total remaining time for the source check are displayed on the bottom status bar as the short count time and the long count time, respectively. At the end of all count cycles, the average detection efficiency is calculated.

If the average measured detection efficiency is not within the percent error limits established in the Preferences form, the software will indicate that the CAM has failed the source check. If the CAM fails the tritium source check, the dialogue box will state "Failed Tritium Source Check" and will present the user with the options to Retry or Cancel. Retry will take the user back to the beginning of the tritium source routine. Cancel will cancel the Source Check utility. 
Upon exiting the Source Check window, the source check results (including information on failures) are written to the file "C: $\mathrm{OS} 3700 \backslash$ Source Check mm-dd-yyyy.txt" where mm-dd-yyyy is the month, day, and year the source check was performed. If multiple source checks are performed on the same day, the results are appended to the end of the file. Figure 3.11 shows a complete Source Check run.

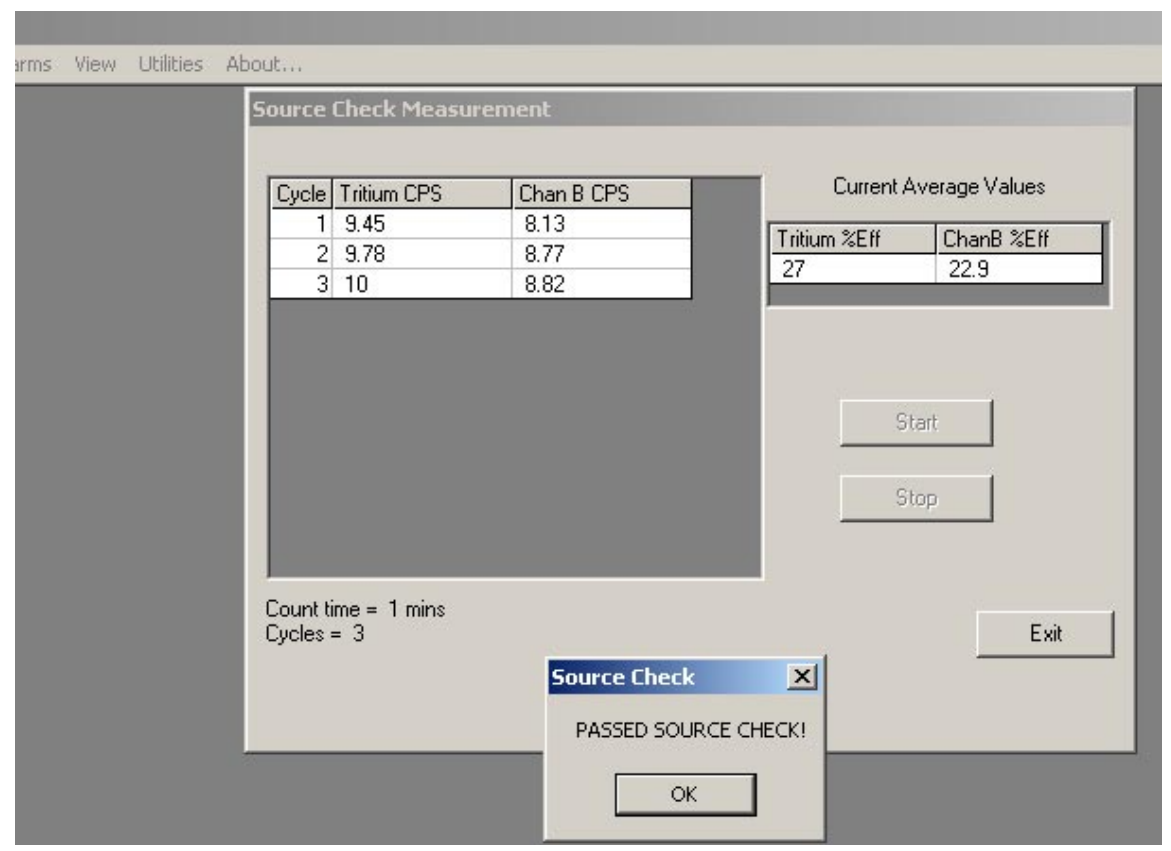

Figure 3.11. Source Check Utility

\subsubsection{Background}

The background values for the Tritium Channel and Channel B calculated concentration readings are determined by clicking on Utilities|Background. This utility runs a background measurement to determine the intrinsic background of tritium and other gases (Figure 3.12). It should be run without any radiological sources in the instrument.

\section{Caution: Storing these values during a background check voids the instrument calibration.}

In the Background window, enter the desired "count time," in minutes, for the background count. The value entered must be between 1 and 10 minutes. Enter the desired "number of cycles." Each count cycle will perform the time period entered under count times. Acceptable values for the number of count cycles are from 1 to 10 .

Click on Start to begin the background measurement. Click $O K$ on the window stating "Be sure to disconnect the tritium monitor from any stack or room air sampling equipment. Click $O K$ when ready to begin background." At the end of each count cycle, the cps and the average counts per minute (cpm) are shown. The time remaining in the count time, per cycle, is indicated on the status bar. To stop the background count, click the Stop button. To exit the background count box, click the Exit button (Figure 3.12).

After all count cycles are complete, the average background count rates, in cpm, will be displayed. To store these values in the registry, click the Store Bkg button. Click Yes to update the stored background 
values. Click No to restore the existing values. Click $O K$ on the window stating, "Background values and the QA database have been updated."

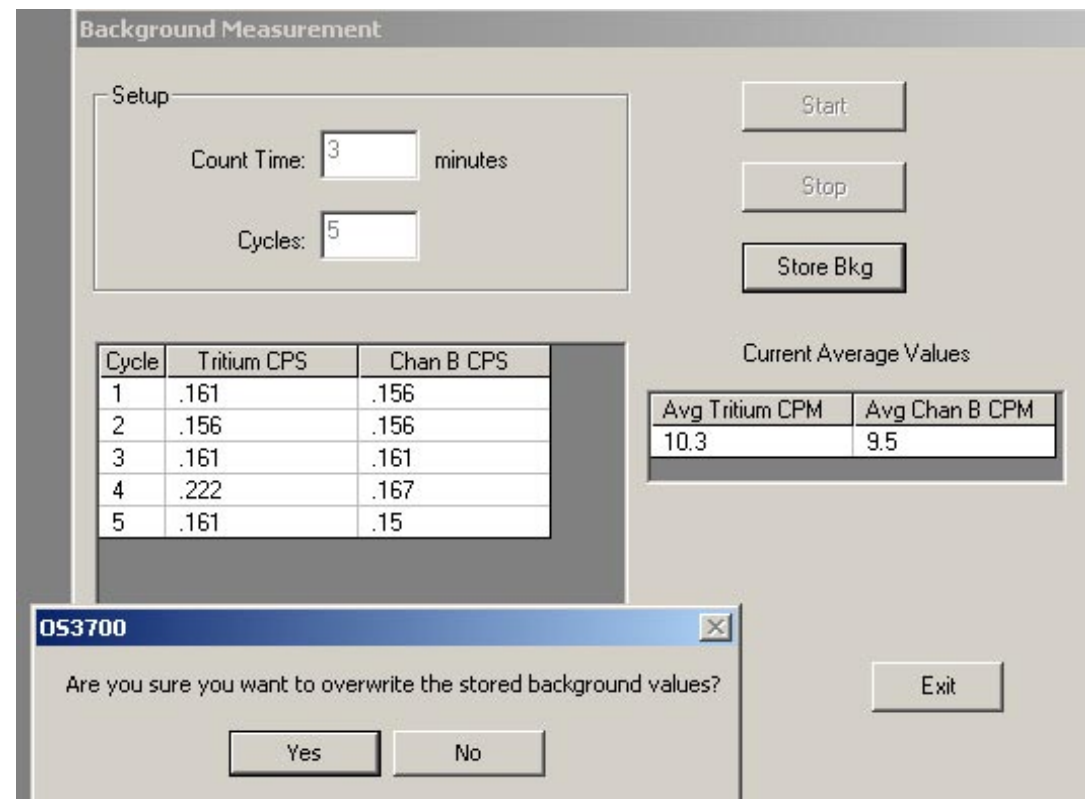

Figure 3.12. Completed Background Window

Note: The Background utility should be run before running efficiencies since background is subtracted from the gross counts (Equation 3.1). The following utilities calculate the efficiency of the detector and should be run only as part of the instrument calibration.

\subsubsection{Check Source Efficiency}

To run the check source efficiency, go to Utilities|Check Source Efficiency. In the Efficiency window, set the Count Time and the number of Cycles. Enter the desired count time, in minutes, for the efficiency count (Figure 3.13). The value entered must be between 1 minute and 10 minutes. Enter the desired number of times the count will cycle. Each cycle will perform for the time period under Count Time. Acceptable values for the number of count cycles are between 1 and 10 .

Caution: Storing these values during an efficiency check voids the instrument calibration. 


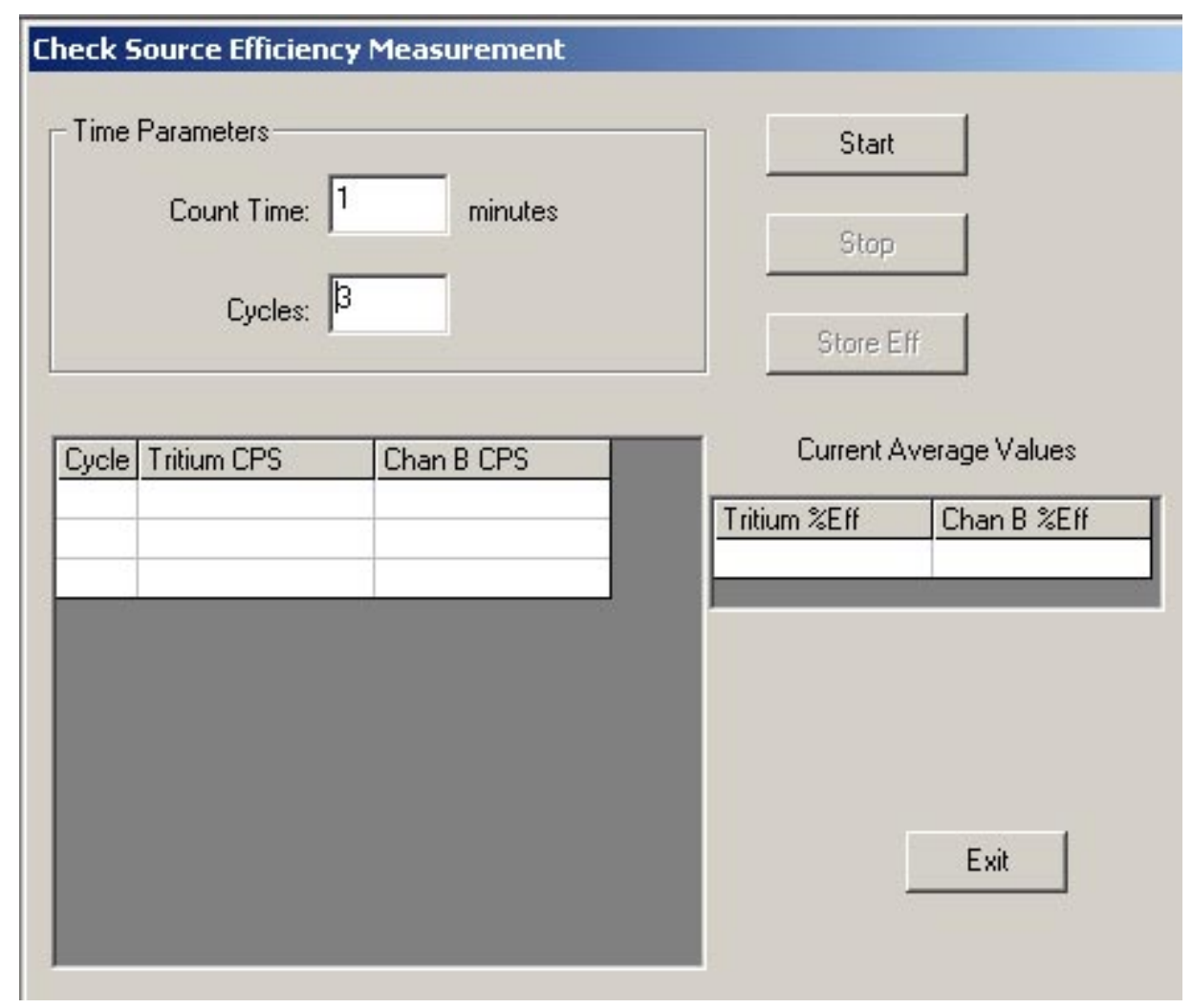

Figure 3.13. Check Source Efficiency Utility Window

Insert the source to be used for Check Source Efficiency. Press Start to begin the detection measurement. Verify the source information is correct and click OK. Click Cancel if the check source information is incorrect and go to the Parameters|Preferences menu to make changes and restart the efficiency utility. Verify the monitor is disconnected from any room air and Click $O K$ on the window that states "Be sure to disconnect the tritium monitor from any stack or room air sampling equipment. Press $O K$ when ready to begin efficiency measurement."

As the Check Source Efficiency utility runs, the cps for the Tritium Channel and Channel B are shown in the table. Once the efficiency measurement counting is complete, both Tritium Channel cps and Channel B cps tables will be filled in, and an average efficiency percent will be provided. To save the efficiency, click the Store Eff button and click Yes to update existing stored check source efficiency values.

\subsubsection{Tritium Efficiency}

From the Utility drop-down menu, select Tritium Efficiency. In the Tritium Efficiency window, set the Count Time in minutes and the number of Cycles. Acceptable values for the number of minutes and count cycles are from 1 to 10 .

Click Start to begin the detection efficiency measurement. A dialogue box will appear asking for the tritium calibration source gas concentration to be entered. Enter the concentration in $\mu \mathrm{Ci} / \mathrm{l}$ (Figure 3.14). Click OK. Verify the tritium gas source is connected following the calibration procedure. As the Tritium Efficiency utility runs, the tritium cps and the average efficiency values will be displayed. 


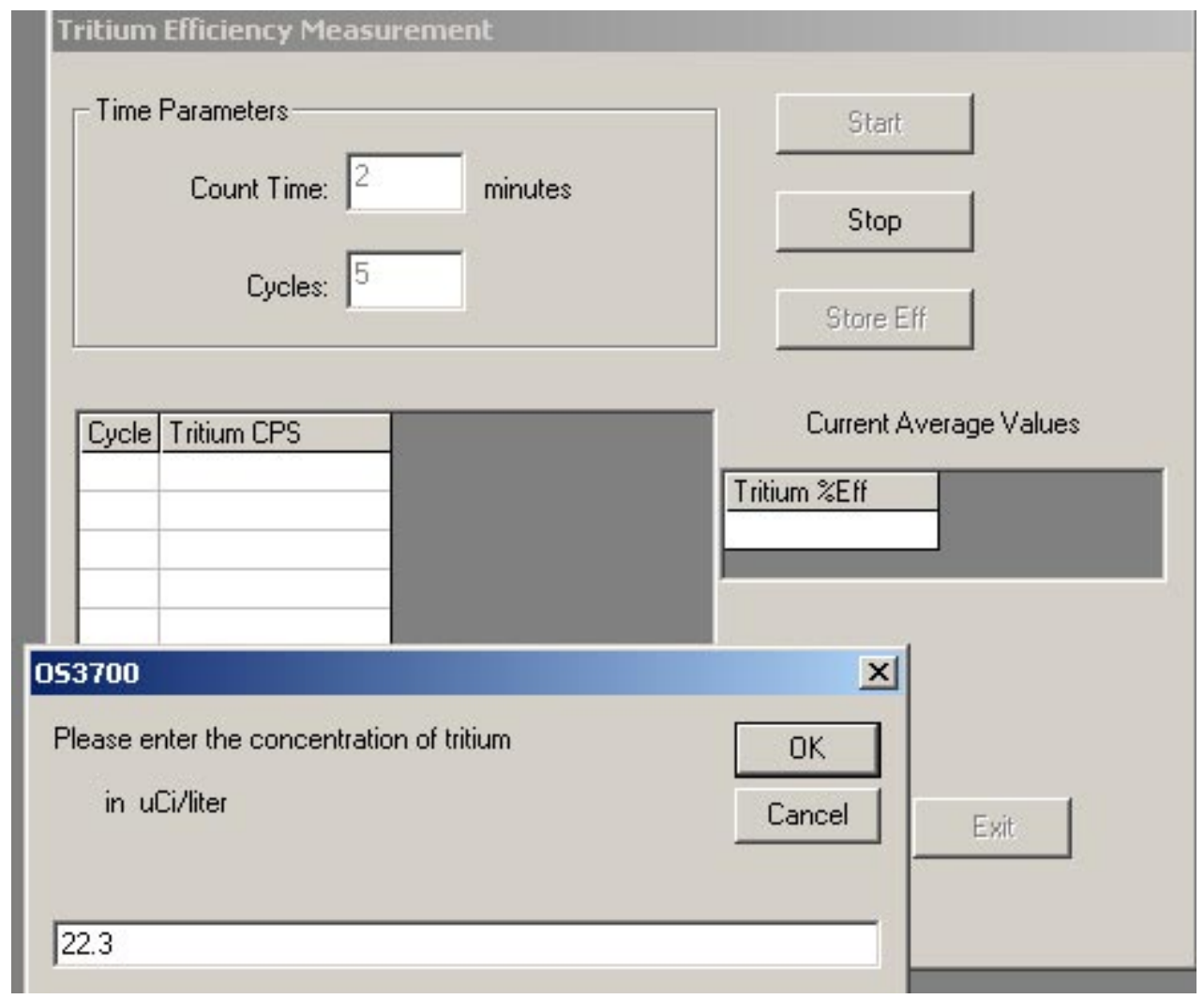

Figure 3.14. Tritium Efficiency Measurement Source Concentration Entry Window

The completed tritium cps table will indicate when the efficiency measurement is finished, and the window will show an average efficiency when counting has ended. To save the efficiency, click the Store Eff button and click Yes to update existing stored tritium efficiency values.

\subsubsection{Channel B Efficiency}

The Channel B efficiency can be accomplished two ways. During the calibration procedure, a measured efficiency, which was found external to the software utility, can be entered manually (Figure 3.15). Once Channel B Efficiency is selected from the Utilities menu, the efficiency is manually entered by typing the value in percent format and clicking on Store. 


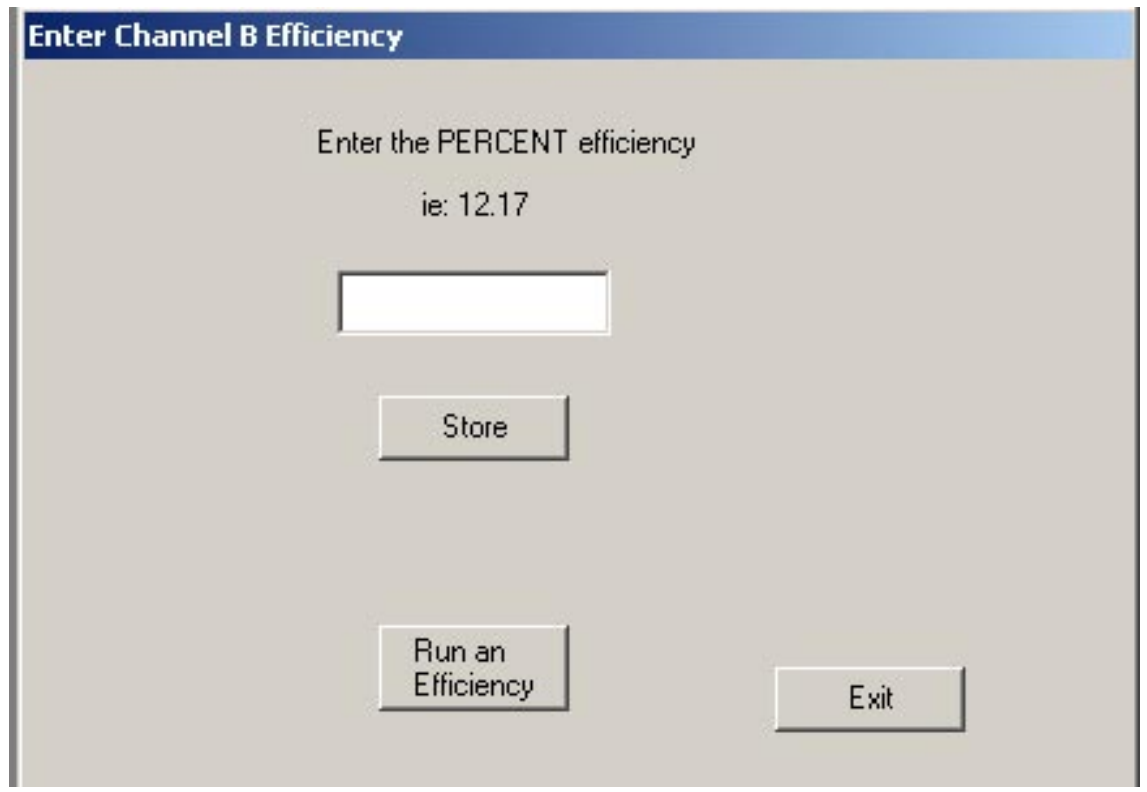

Figure 3.15. Channel B Efficiency Manual Entry Window

The second method for Channel B efficiency is accomplished by clicking on Run an Efficiency on the first Channel B Efficiency window. Set count time and cycles as with the other efficiency utilities, and click Start. Enter the concentration for the calibration source being used in $\mu \mathrm{Ci} / 1$ and click $O K$. Verify the Channel B calibration source is connected following the calibration procedures. Once the efficiency run is finished, click Store Eff to overwrite the Channel B efficiency value (Figure 3.16).

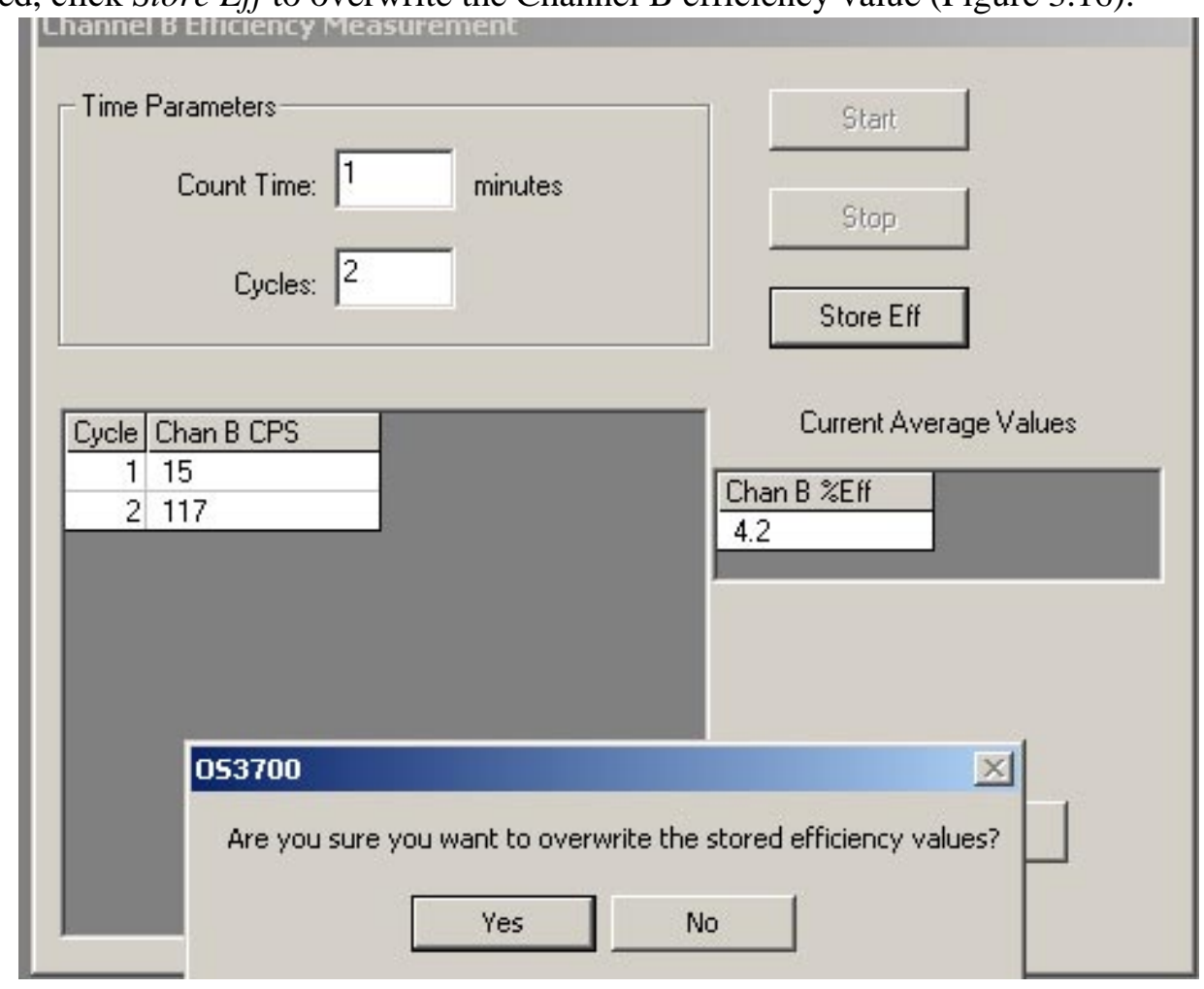

Figure 3.16. Channel B Efficiency Store Values Window 


\subsubsection{About Drop-Down Menu}

Selecting About provides the user information on the PNNL OS3700 software.

\subsection{Detector Plateau}

To manually run a detector voltage plateau using the PNNL OS3700 software, follow the steps below:

1. Enter the desired count time for the plateau measurement as both the "short count time" and the "long count time" shown in Section 3.2.6.1, Count Times. Plateaus are usually run for short periods of time such as 1 to 5 minutes. Confirm that Rolling Average is disabled in the Count Times window.

2. Set the voltage on the LB110 front panel to the lowest desired voltage (such as $100 \mathrm{~V}$ ).

3. Insert a hard check source or a gas source into the front of the LB110.

4. Start the acquisition by selecting Acquire|Start and wait for the long count time to be completed.

5. Open the database for the PNNL OS3700 software (typically named "Tritium97.MDB"); select the table named "TritiumRawData."

6. Go to the last entry in the database table and record the values from the "TritCounts" and "ChanB" field entries. These are the total counts that were just registered (no background subtraction) from the two channels of the LB110.

7. Increase the voltage on the front panel of the LB110.

8. Select Acquire|Stop from the menu.

9. Repeat steps $4-8$ for the number of voltage steps desired.

The raw data should be plotted as counts in the Tritium Channel and Channel B versus the voltage setting. The voltage should be selected so it is in or near the center of the plateau region for both channels.

\subsection{Real-Time Operation}

When in real-time data acquisition mode, the normal operational mode for the software, the system display shown in Figure 3.17 will be visible to the operator. This screen has several features, which are described below. 


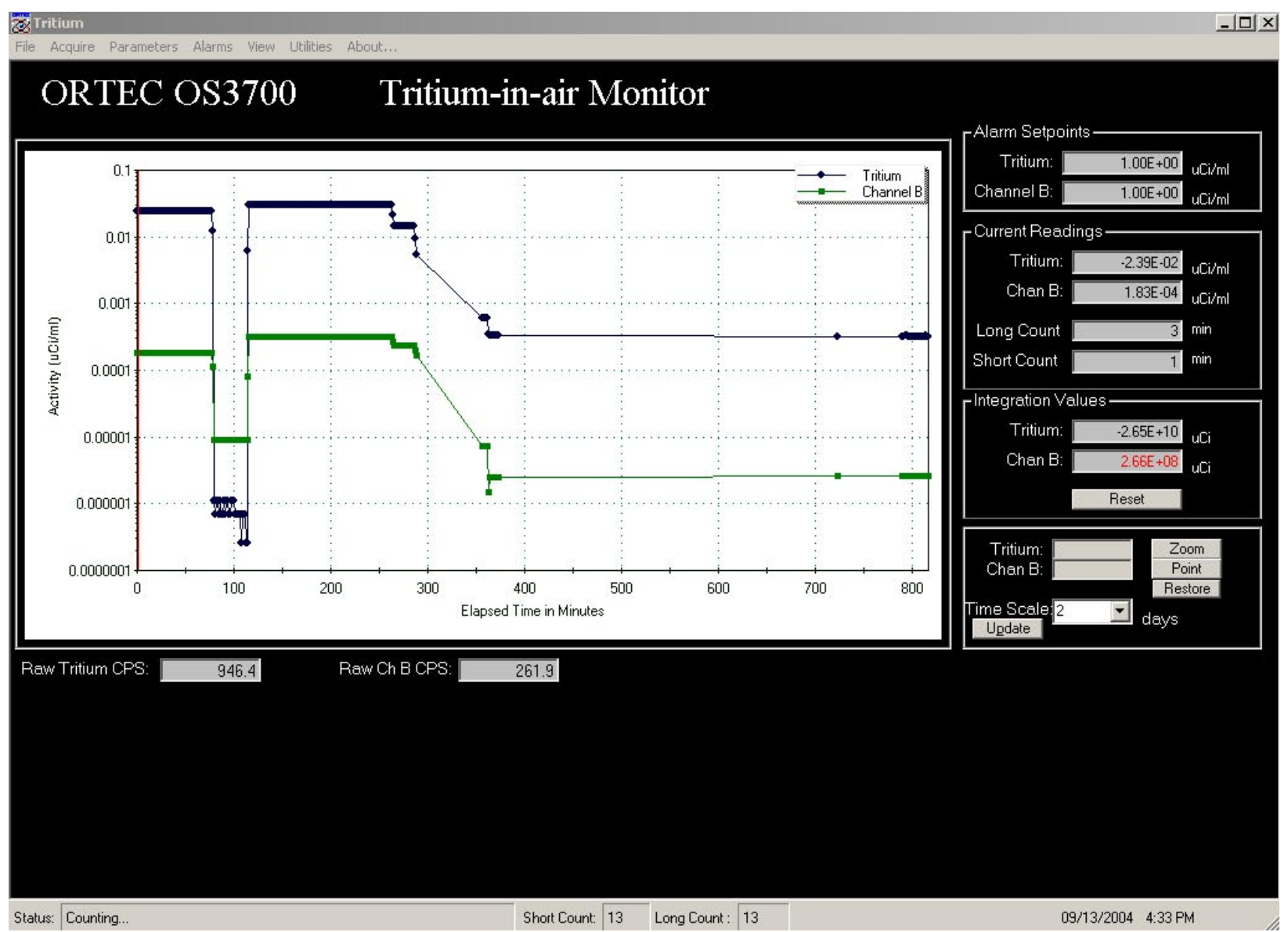

Figure 3.17. Main Real-Time, Interactive Graph Window

- The menu across the top shows the options available in the acquisition mode. Utilities, including Count Time settings, are only available after stopping the counting process by clicking on Acquire|Stop. See Section 3.2 for description of menu options.

- Raw Tritium cps and Raw Channel B (Ch B) cps are shown in the boxes directly below the interactive graph or strip chart.

- The status bar at the bottom left displays messages regarding the counting and failure status of both channels.

- Short Count and Long Count display next to Status bar show count time remaining as they decrement. Real time date, hour, and minutes are also displayed on the bottom bar.

\subsubsection{Strip-Chart Display and Elapsed Interactive Display}

The left-hand side of the screen graphically displays the Tritium Channel and Channel B data over a userselected number of days, between 1 and 30. After choosing the time scale, the operator must press the Update button (Figure 3.18). The graph will update the data in the display for just the last $n$ number of days where $n$ is the value just entered by the operator (Figure 3.19). 
Only long counts are graphed, and the values displayed are the activity concentration values in $\mu \mathrm{Ci} / \mathrm{ml}$. The operator can also zoom in on any section of the graph for more detail of a trend or specific data. To do this, the operator presses the Zoom button and moves the mouse over the graphical display. The cursor will turn into a "magnifying" glass. The operator can click and drag over the $\mathrm{x}$ - and $\mathrm{y}$-area of the graph to zoom in and out. The graph will automatically update to the zoomed-in region (Figure 3.19). The Restore button is used to set the graph back to normal display. The operator can obtain the elapsed time and activity concentration data of any data by clicking on the Point button and moving the mouse over the graphical display. The mouse will turn to a "crosshair" that allows the operator to select data. Once the point is selected on the graph, the corresponding concentrations are displayed next to both the Tritium Channel and Channel B headings in the Elapsed readings box.

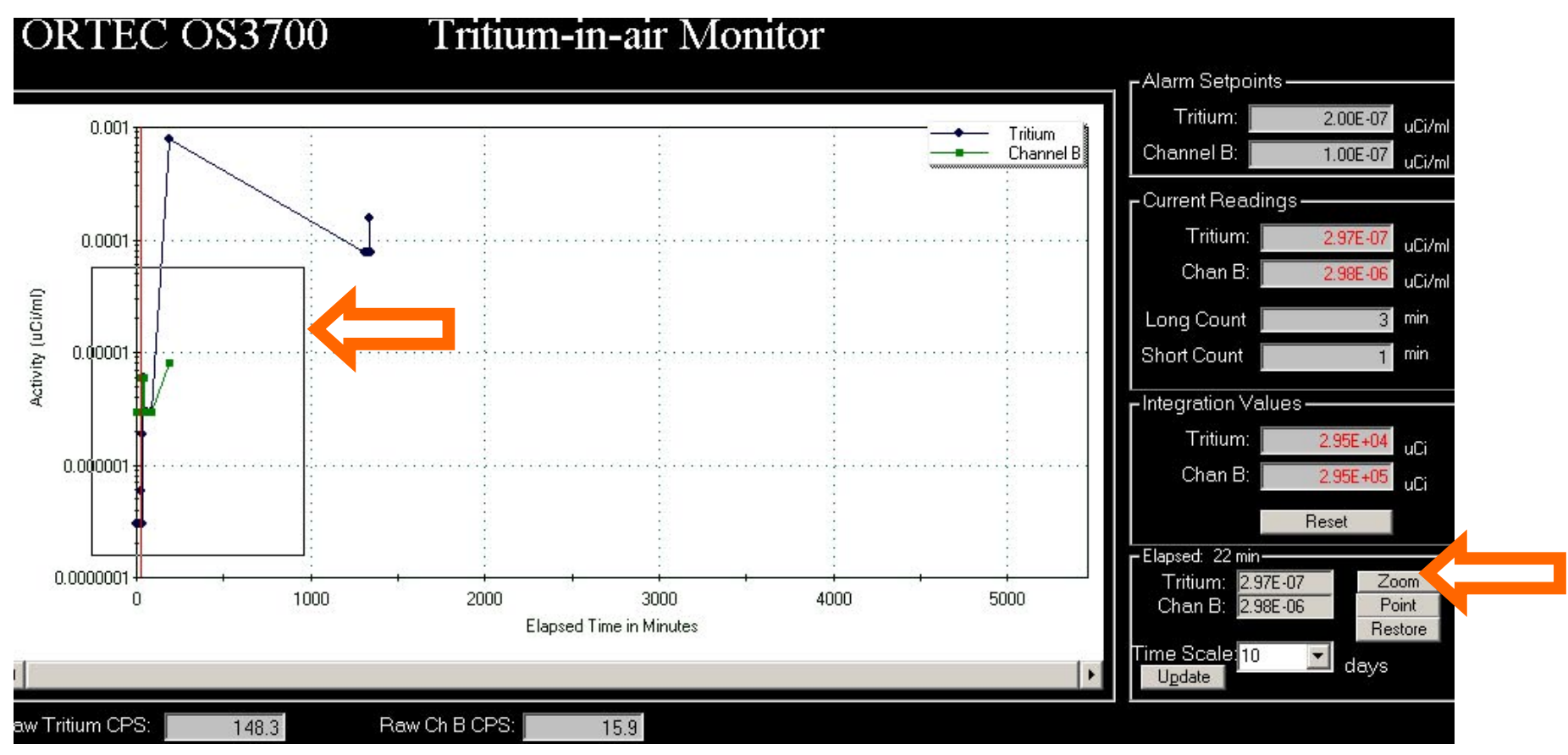

Figure 3.18. Elapsed Interactive Display

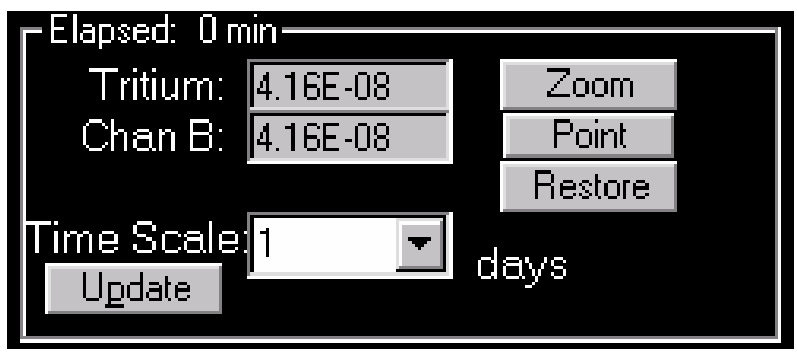

Figure 3.19. Strip Chart Display

\subsubsection{Current Readings}

The Current Readings screen includes indicators from the last reading for the Tritium Channel and Channel B activity concentration. These values are updated after every short count interval. Units for each of these parameters are shown on the screen. When the rolling average feature is used, the average 
short count data (for the number of data points selected) are displayed at the end of every short count measurement (see Figure 3.20).

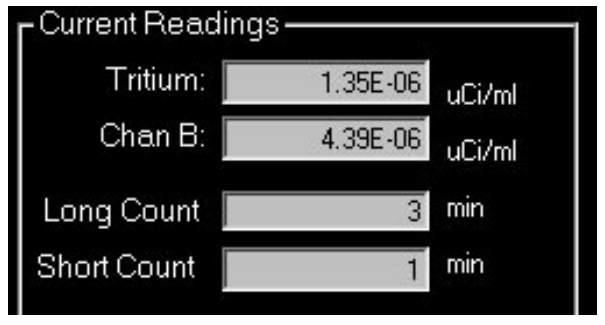

Figure 3.20. Current Readings Display

\subsubsection{Alarm Set Points}

The current alarm set points for the Tritium Channel and Channel B activity concentration values are displayed on the right-hand side of the screen (Figure 3.21).

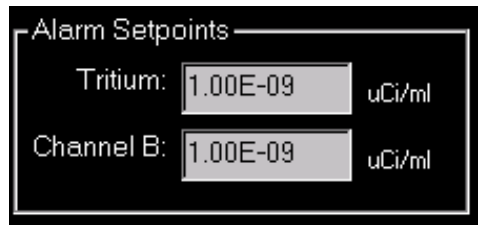

Figure 3.21. Alarm Set Point Display

\subsection{Integration Values}

The current Tritium Channel and Channel B integrated activity is displayed on the right-hand side of the screen (Figure 3.22). This part of the screen also allows the operator to manually reset the integration values logged in the database to zero. To reset the integration log, the operator simply presses the Reset button. A warning message will appear allowing the operator to cancel this operation. For the Auto Reset of integration values option, the integration values will be automatically reset on or near midnight every day.

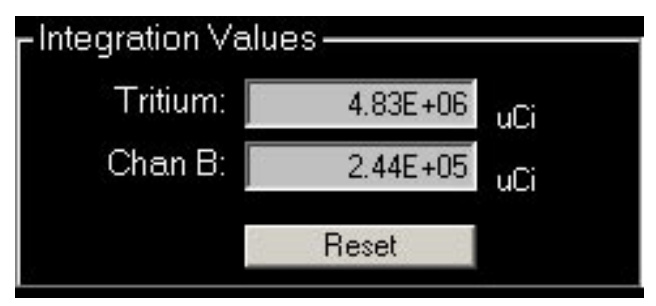

Figure 3.22. Integration Values Recored Every Long Count

\subsection{Calculations}

There are several values relating to alarms for activity of the sample as measured by the detection system. They are Radiation Concentration, Integral Activity, and Fail Thresholds. 


\section{Calculation of Activity Concentrations}

The current reading activity concentration in the sample chamber is calculated in $\mu \mathrm{Ci} / \mathrm{ml}$. Any userselected display units are calculated from this value. The volume of air is constant in the LB110 and is preset in the software to be $260 \mathrm{ml}(1300 \mathrm{ml}$ chamber in a 4:1 P-10 to air-mix ratio). The activity is calculated by dividing the number of counts in each channel by the count time to determine cps. The background is subtracted, and these corrected values are divided by the efficiency of the detector and converted from $\mathrm{Bq}$ to $\mu \mathrm{Ci}$. Equations 3.2 and 3.3 demonstrate the activity calculations:

$$
A_{\text {tot }}=\frac{\text { Gross Counts }}{\text { Count Time (in seconds) }}-A_{0}
$$

and

$$
B_{\text {tot }}=\frac{\text { Gross Counts }}{\text { Count Time (in seconds) }}-B_{0}
$$

where $\mathrm{A}_{\text {tot }}$ and $\mathrm{B}_{\text {tot }}$ are background corrected activities, $\mathrm{A}_{0}$ and $\mathrm{B}_{0}$ are background counting rates, and all results are in cps. $A_{\text {tot }}$ is for tritium, and $B_{\text {tot }}$ is for Channel $B$ gases.

The "Gross Counts" are the total number of counts acquired by the LabMaster ${ }^{\mathrm{TM}}$ card for a particular short count time period. Before reaching the software, the delta change in counts is calculated by subtracting the previous measured count from the total to arrive at the current measured count. This is done at the end of each short count time since the LabMaster ${ }^{\mathrm{TM}}$ card counters are not cleared before starting the next count, unless the CAM is in an alarm state. The Gross Counts are calculated by the Equation 3.4.

$$
G C=T C_{i}-T C_{i-1} \text { for } i \geq 2
$$

where GC is the Gross Counts in a short count period (for either the Tritium Channel or Channel B counter), and TC is the Total Counts in the counter at the end of the $\mathrm{i}^{\text {th }}$ short count period.

Activity concentrations for Tritium and Channel B gases are given in Equations 3.5 and 3.6, respectively.

$$
A_{\text {Art }}=\frac{A_{\text {tot }}}{E f f_{a} \times 37,000 \times 260}
$$

and

$$
B_{\text {Art }}=\frac{B_{\text {tot }}}{E f f_{b} \times 37,000 \times 260}
$$

where $\mathrm{A}_{\mathrm{Art}}$ and $\mathrm{B}_{\mathrm{Art}}$ are artificial activity (i.e., the radiation concentration) in $\mu \mathrm{Ci} / \mathrm{ml} ; \mathrm{Eff}_{\mathrm{a}}$ and $\mathrm{Eff} \mathrm{b}_{\mathrm{b}}$ are the efficiencies of the Tritium and Channel B counters. 


\subsubsection{Integral Activity}

Integral Activity is calculated in $\mu \mathrm{Ci}$ and is the total activity released through the stack. The integral activity is summed to the previous value at the end of each long count time. Integral activity is found by summing each of the radiation concentrations multiplied by the volume of air through the stack for that short count time (Equation 3.7). The Integral Activity is reset each day at midnight.

$$
A_{I}=\sum_{i=1}^{L T / S T} \dot{A}_{i} * F T_{i}
$$

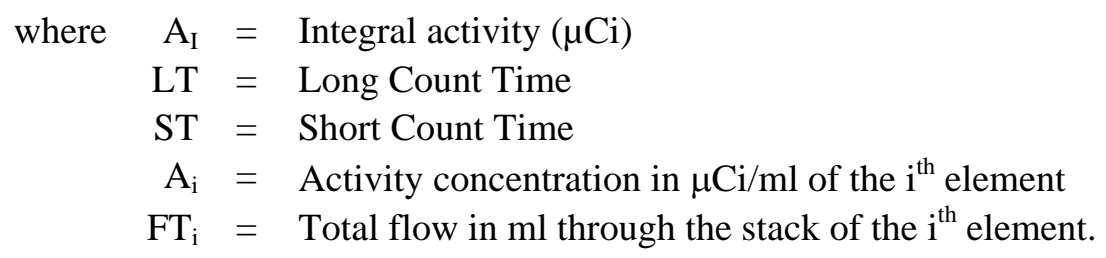

\subsubsection{Fail Threshold}

The Fail Threshold is an indicator that the detection system is not functioning properly. In the absence of any artificial radioactivity, the system should accumulate counts in response to natural activity. By setting a count rate in any of the fields, the system will check to make sure the count rate is detected in every short measuring time period. If it is not, an alarm is generated. The alarm, referred to as CAM Function, will be generated if either the Tritium Channel or Channel B fail threshold is not exceeded. The user cannot set the count time. It is equal to the short measuring time. 


\subsection{Database Tables}

The data for the PNNL OS3700 software are stored to a number of tables in a Microsoft Access ${ }^{\circledR}$ compatible database format. The name of the database is Tritium97.MDB, and it is found in the C:ISSEMS ISEMSDBS directory.

\subsection{Database Table Descriptions}

The database consists of the following tables.

Data fields in the tables listed in Table 4.1 are described in Tables 4.2, 4.3, 4.4, and 4.5.

Table 4.1. Tables in the PNNL OS3700 Software Database

\begin{tabular}{|l|l||}
\hline \multicolumn{1}{|c|}{ Table Name } & \multicolumn{1}{c|}{ Description } \\
\hline TritiumIntegrationLog & $\begin{array}{l}\text { Holds the integration parameter information, such as the starting and ending } \\
\text { date and time of each integration period }\end{array}$ \\
\hline TritiumQATable & $\begin{array}{l}\text { Holds the current and historical quality assurance data used by the PNNL } \\
\text { OS3700 software. The last entry (most recent) is used by the software for all } \\
\text { calculations. Each time a parameter is changed, a new record is generated } \\
\text { with the time/date of the change. }\end{array}$ \\
\hline TritiumRawData & $\begin{array}{l}\text { Holds all long count time data including time/date stamp, raw data, calculated } \\
\text { concentrations, flow totals, and calculated integral activity }\end{array}$ \\
\hline TritiumShortCountData & $\begin{array}{l}\text { Holds all short count time data including time/date stamp, raw dataled } \\
\text { concentrations, and flow totals }\end{array}$ \\
\hline
\end{tabular}

Table 4.2. Tritium Integration Log

\begin{tabular}{|l|l||}
\hline Field Name & Description \\
\hline IntegrationLog & $\begin{array}{l}\text { Unique identifier. The newest record is the last number. This record is generated } \\
\text { each time the Reset button is clicked on the Integration section of the main screen. } \\
\text { The value in this field is automatically generated. }\end{array}$ \\
\hline StartDate & Date/time stamp when the integration period began \\
\hline EndDate & Date/time stamp when the integration period ended \\
\hline
\end{tabular}


Table 4.3. Tritium QA Data

\begin{tabular}{|l|l|}
\hline \multicolumn{1}{|c|}{ Field Name } & \multicolumn{1}{c|}{ Description } \\
\hline TritQAID & $\begin{array}{l}\text { Unique identifier for correlating the QA data with the measured data. The value in this } \\
\text { field is automatically generated. }\end{array}$ \\
\hline TritiumEff & Entered tritium efficiency as a fractional number (between zero and one, typically) \\
\hline TritumBKG & Entered tritium background count rate value in cps \\
\hline ChanBEff & $\begin{array}{l}\text { Entered efficiency for Channel B as a fractional number (between zero and one, } \\
\text { typically) }\end{array}$ \\
\hline ChanBBKG & Entered background count rate value for Channel B in cps \\
\hline TritCalDate & Date the Tritium Channel efficiency value was stored \\
\hline ChBCalDate & Date the Channel B efficiency value was stored \\
\hline BKGDate & Date the Tritium Channel and Channel B background value was stored \\
\hline
\end{tabular}

Table 4.4. Tritium Raw Data

\begin{tabular}{||l|l||}
\hline \multicolumn{1}{|c||}{ Field Name } & \multicolumn{1}{c||}{ Description } \\
\hline RawIndex & $\begin{array}{l}\text { Unique identifier. The newest record is the last number. The value in this field is } \\
\text { automatically generated. }\end{array}$ \\
\hline TritConc & Average tritium concentration value in $\mu \mathrm{Ci} / \mathrm{ml}$ during the long count time \\
\hline ChanBConc & Average Concentration value of Channel B in $\mu \mathrm{Ci} / \mathrm{ml}$ during the long count time \\
\hline TritInt & Integrated tritium activity calculated based on the Stack Flow Rate in $\mu \mathrm{Ci}$ \\
\hline ChanBInt & Integrated Activity for Channel B calculated based on the Stack Flow Rate in $\mu \mathrm{Ci}$ \\
\hline CAMStatus & Not used. Always "NULL" value. \\
\hline StackFlowRate & $\begin{array}{l}\text { Average stack flow rate either measured or fixed value in } \mathrm{m}^{3} / \mathrm{hr}(\text { averaged over the } \\
\text { long count time) }\end{array}$ \\
\hline StackFlowTotal & Calculated stack flow total for the long measuring time in $\mathrm{m}^{3}$ \\
\hline SampleFlowRate & Flow rate through LB110 measuring chamber. Fixed value of $260 \mathrm{ml} / \mathrm{min}$. \\
\hline SampleFlowTotal & Calculated sample flow total for the long measuring time in $\mathrm{cm}^{3}$ \\
\hline RawDate & Date stamp for the data entered in this record \\
\hline RawTime & Time stamp for the data entered in this record \\
\hline TritCounts & Total gross counts during the long measuring period for the Tritium Channel \\
\hline ChanBCounts & Total gross counts during the long measuring period for Channel B \\
\hline CountTime & Total long count time for this record \\
\hline TritQAID & Correlated identification number to the record in the TritiumQATable data \\
\hline
\end{tabular}


Table 4.5. Tritium Short Count Data

\begin{tabular}{|l|l||}
\hline \multicolumn{1}{|c||}{ Field Name } & \multicolumn{1}{c|}{ Description } \\
\hline RawIndex & $\begin{array}{l}\text { Unique identifier. The newest record is the last number. The value in this field is } \\
\text { automatically generated. }\end{array}$ \\
\hline TritConc & Calculated tritium concentration value in $\mu \mathrm{Ci} / \mathrm{ml}$ during this measurement period \\
\hline ChanBConc & $\begin{array}{l}\text { Calculated concentration value in Channel B in } \mu \mathrm{Ci} / \mathrm{ml} \text { during this measurement } \\
\text { period }\end{array}$ \\
\hline TritInt & $\begin{array}{l}\text { Last calculated integration value for tritium activity from TritiumRawData table. } \\
\text { This field is not calculated during the short count time periods. Value is in } \mu \text { Ci. }\end{array}$ \\
\hline ChanBInt & $\begin{array}{l}\text { Last calculated integration value for Activity in Channel B from TritiumRawData } \\
\text { table. This field is not calculated during the short count time periods. Value is in } \\
\mu \text { Ci. }\end{array}$ \\
\hline CAMStatus & Not used. Always "NULL" value. \\
\hline StackFlowRate & $\begin{array}{l}\text { Actual stack flow rate either measured or fixed value in } \mathrm{m}^{3} / \mathrm{hr} \text { for the short count } \\
\text { period }\end{array}$ \\
\hline StackFlowTotal & Calculated stack flow total for the short count period in $\mathrm{m}^{3}$ \\
\hline SampleFlowRate & Flow rate through LB110 measuring chamber. Fixed value of $260 \mathrm{ml} / \mathrm{min}$ \\
\hline SampleFlowTotal & Calculated sample flow total for the short measuring time in $\mathrm{cm}^{3}$ \\
\hline RawDate & Date stamp for the data entered in this record \\
\hline RawTime & Time stamp for the data entered in this record \\
\hline TritCounts & Total gross counts during this short measuring period for the Tritium Channel \\
\hline ChannelBCounts & Total gross counts during this short measuring period for Channel B \\
\hline CountTime & The short count time for this record \\
\hline TritQAID & Correlated identification number to the record in the TritiumQATable data \\
\hline
\end{tabular}

\subsection{Calculating Data from the Tables}

Three of the database tables are integrated and can be used to calculate and verify the data stored in them. The following discussion (Section 5.0) describes these relationships in detail and goes through an example calculation. 


\subsection{Process}

The data starts with the accumulation of counts in the LabMaster ${ }^{\mathrm{TM}}$ card. The calculation of the activity concentration and integral activity is described earlier in this manual (Section 3.6). The process is described below:

1. The LabMaster ${ }^{\mathrm{TM}}$ card timer is set to the short count time.

2. The counters are cleared.

3. The LabMaster ${ }^{\mathrm{TM}}$ card begins acquiring counts.

4. At the end of the preset short count time, the software retrieves the number of counts in the Tritium and Channel B counters along with the count time. These values are stored for later use in the software and for the database tables.

5. The Tritium and Channel B concentrations are calculated for the current short count time.

6. The short count data is stored to the database, if the Save Short Count Data to Database option is enabled.

7. The concentrations are checked against alarm settings.

8. The count time is incremented by short count time.

9. Steps 3 through 8 are repeated until either an alarm condition exists (at which time the long count time is made equal to the short count time), or the long count time is reached.

10. The long count time and final short count time calculations are performed.

11. Data are stored to the database and plotted to the screen as necessary/required by the operator.

12. The process continues until the user terminates the program, or the computer is shut off.

\subsection{Example}

The following set of short count data (Table 5.1) is used to step the reader through the example. The long count time is equal to 3 minutes, and the short count time is equal to 1 minute. The stack flow rate is fixed at $140,000 \mathrm{ft}^{3} / \mathrm{min}$.

The QA data are: $\quad \begin{aligned} \text { QATableID } & =3 \\ \text { TritEff } & =0.50 \\ \text { TritBKG } & =0.30 \mathrm{cps} \\ \text { ChanBEff } & =0.85 \\ \text { ChanBBKG } & =0.70 \mathrm{cps} .\end{aligned}$


Table 5.1. Example Data

\begin{tabular}{|c|c|c|c||}
\hline $\begin{array}{c}\text { Short Count } \\
\text { Period }\end{array}$ & $\begin{array}{c}\text { Tritium } \\
\text { Counts }\end{array}$ & $\begin{array}{c}\text { Channel B } \\
\text { Counts }\end{array}$ & $\begin{array}{c}\text { Time } \\
\text { (seconds) }\end{array}$ \\
\hline 1 & 35 & 150 & 60 \\
\hline 2 & 75 & 295 & 60 \\
\hline 3 & 150 & 460 & 60 \\
\hline
\end{tabular}

The following data (Table 5.2) would appear in the TritiumRawData or the TritiumShortCountData tables,

Table 5.2. Database Records from Example

\begin{tabular}{|c|c|c|c|}
\hline \hline Cycle & $\begin{array}{c}\text { Tritium } \\
\text { Counts }\end{array}$ & $\begin{array}{c}\text { Channel B } \\
\text { Counts }\end{array}$ & $\begin{array}{c}\text { Time } \\
\text { (seconds) }\end{array}$ \\
\hline 1 & 35 & 150 & 60 \\
\hline 2 & 75 & 295 & 120 \\
\hline 3 & 150 & 460 & 180 \\
\hline
\end{tabular}

Table 5.3 shows the accumulation of short count data and the calculation of the activity for the three cycles in the example.

Table 5.3. Calculated Data from Example

\begin{tabular}{|r|c|c|r|r|r|r|}
\hline $\begin{array}{c}\text { Count Time } \\
\text { (in min) }\end{array}$ & $\begin{array}{c}\text { Tritium } \\
\text { Counts }\end{array}$ & $\begin{array}{c}\text { Chan B } \\
\text { Counts }\end{array}$ & $\begin{array}{c}\text { Trit Net } \\
\text { Rate (cps) }\end{array}$ & $\begin{array}{c}\text { Chan B Net } \\
\text { Rate (cps) }\end{array}$ & $\begin{array}{c}\text { Trit Activity } \\
(\boldsymbol{\mu} \mathbf{C i} / \mathbf{m l})\end{array}$ & $\begin{array}{c}\text { Chan B Activity } \\
(\boldsymbol{\mu C i} / \mathbf{m l})\end{array}$ \\
\hline 1 & 35 & 150 & 0.28 & 1.80 & $5.82 \mathrm{E}-08$ & $2.20 \mathrm{E}-07$ \\
\hline 1 & 75 & 295 & 0.95 & 4.22 & $1.98 \mathrm{E}-07$ & $5.16 \mathrm{E}-07$ \\
\hline 1 & 150 & 460 & 2.20 & 6.97 & $4.57 \mathrm{E}-07$ & $8.52 \mathrm{E}-07$ \\
\hline
\end{tabular}

The short count data table will contain the following data (Table 5.4) from this example.

Table 5.4. Tritium Short Count Data Table Results from Example

\begin{tabular}{|r|c|r|r|r|r|r|r|r|r|r|r|r|r|r|}
\hline \hline RawIndex & TritConc & ChanBConc & TritInt & ChanBInt & $\begin{array}{c}\text { CAM } \\
\text { Status }\end{array}$ & StackFlowRate & StackFlowTotal & $\begin{array}{c}\text { SampleFlow } \\
\text { Rate }\end{array}$ & $\begin{array}{c}\text { SampleFlow } \\
\text { Total }\end{array}$ & RawDate & RawTime & TritCounts & $\begin{array}{l}\text { ChanB } \\
\text { Counts }\end{array}$ & $\begin{array}{c}\text { Count } \\
\text { Time }\end{array}$ \\
\hline 14 & $5.82 \mathrm{E}-08$ & $2.20 \mathrm{E}-07$ & 0 & 0 & & 140000 & 3964.4 & 260 & 260 & $8 / 21 / 01$ & $1: 34: 46$ PM & 35 & 150 & 60 \\
\hline 15 & $1.98 \mathrm{E}-07$ & $5.16 \mathrm{E}-07$ & 0 & 0 & & 140000 & 3964.4 & 260 & 260 & $8 / 21 / 01$ & $1: 35: 50 \mathrm{PM}$ & 75 & 295 & 60 \\
\hline 16 & $4.57 \mathrm{E}-07$ & $8.52 \mathrm{E}-07$ & 0 & 0 & & 140000 & 3964.4 & 260 & 260 & $8 / 21 / 01$ & $1: 36: 54 \mathrm{PM}$ & 150 & 460 & 60 \\
\hline
\end{tabular}

The long count table will contain the following data (Table 5.5) from this example.

Table 5.5. Tritium Raw Data Table Results from Example

\begin{tabular}{|c|c|c|c|c|c|c|c|c|c|c|c|c|c|c|}
\hline RawIndex & TritConc & $\begin{array}{c}\text { ChanB } \\
\text { Conc }\end{array}$ & TritInt & ChanBInt & \begin{tabular}{|l|} 
CAM \\
Status
\end{tabular} & \begin{tabular}{|c|}
$\begin{array}{c}\text { StackFlow } \\
\text { Rate }\end{array}$ \\
\end{tabular} & \begin{tabular}{|c|} 
StackFlow \\
Total
\end{tabular} & \begin{tabular}{|c|}
$\begin{array}{c}\text { SampleFlow } \\
\text { Rate }\end{array}$ \\
\end{tabular} & \begin{tabular}{|c|}
$\begin{array}{c}\text { SampleFlow } \\
\text { Total }\end{array}$ \\
\end{tabular} & RawDate & RawTime & TritCounts & $\begin{array}{l}\text { ChanB } \\
\text { Counts }\end{array}$ & \begin{tabular}{|c|} 
Count \\
Time
\end{tabular} \\
\hline 1475 & $2.38 \mathrm{E}-07$ & $5.29 \mathrm{E}-07$ & $2.8274 \mathrm{E}+03$ & $6.2954 \mathrm{E}+03$ & & 140000 & 3964.4 & 260 & 780 & $8 / 21 / 01$ & 1:36:54 PM & 260 & 905 & 180 \\
\hline
\end{tabular}




\subsection{Software Maintenance}

\subsection{Software Development Requirements}

The PNNL OS3700 software was developed using Microsoft Visual Basic 6.0 Professional Edition ${ }^{\circledR}$ for 32-bit Development. As a 32-bit development system, the PNNL OS3700 software is designed to run in the Windows $2000^{\circledR}$ or Windows $\mathrm{NT}^{\circledR}$ operating environments.

Questions or requests for modification of the source code for the PNNL OS3700 software should be directed to the following:

Pacific Northwest National Laboratory

P.O. Box 999, Mail Stop J2-25

Richland, WA 99352

\subsection{Reloading Instructions}

If the operating software for the PNNL OS3700 becomes corrupt, fails to function properly, or otherwise needs to be re-installed, the following procedure may be used to perform the necessary setup:

1. Copy the following files to a floppy diskette:

- Tritium97.MDB (The database with all data stored)

- C:IOS3700\YYMMDD.LOG (location of log files).

2. Start the Windows ${ }^{\circledR}$ Control Panel.

3. Double-click the Add/Remove Software option.

4. Select the $O S 3700$ option in the dialogue box.

5. Click the Add/Remove button to remove the software.

6. Click Yes to confirm that you want to remove the software.

7. Exit the Control Panel when the software has been removed.

8. Select the Start|Run option of the Windows ${ }^{\circledR}$ operating system.

9. Click Browse.

10. Change to the D: $\backslash$ drive or applicable drive for a CD in "My Computer."

11. Double-click the Setup icon in this folder.

12. Click $O K$ from the Run dialogue box.

13. Accept the defaults of the OS3700 setup screens.

14. Click OK when the OS3700 setup has been successfully completed.

15. Optionally, the PNNL OS3700 software can be added to the Windows ${ }^{\circledR}$ Startup group so each time the Operating System starts, the software will automatically start. 


\subsection{Maintenance Schedules and Procedures}

There are six relay outputs controlled by the software. These relays are controlled by a connection to the 25-pin D connector on rear of the LabMaster ${ }^{\mathrm{TM}}$ breakout box. These outputs (numbers one through six) are programmable from the software. Two additional digital outputs are present on the 25-pin D connector, but are not currently used by the software. If any of these relays do not operate correctly (i.e., alarms when there is no alarm or fails to alarm when the level is reached), follow the steps in Table 6.1.

If the checklist fails to remedy the problem, contact the factory for further assistance.

Table 6.1. Relay Output Troubleshooting Checklist

\begin{tabular}{||l|l|l||}
\hline Step & \multicolumn{1}{|c|}{ Procedure } & \multicolumn{1}{|c|}{ If there is a problem, take this next step. } \\
\hline 1 & $\begin{array}{l}\text { Check the ribbon cable } \\
\text { connection at the LabMaster } \\
\text { card on the rear of the computer. }\end{array}$ & $\begin{array}{l}\text { Reconnect a loose. } \\
\text { Repair damaged connector (e.g., bent or } \\
\text { broken pins). }\end{array}$ \\
\hline 2 & $\begin{array}{l}\text { Check electrical terminations at } \\
\text { the breakout box. }\end{array}$ & $\begin{array}{l}\text { Reconnect loose cables. } \\
\text { Repair damaged connector. }\end{array}$ \\
\hline
\end{tabular}


PNNL OS3700 Tritium Monitoring System Software and Hardware Operations Manual Rev. 0

\subsection{References}

None. 